\title{
Trap-Assisted Recombination via Integer Charge Transfer States in Organic Bulk Heterojunction Photovoltaics
}

Qinye Bao, Oskar Sandberg, Daniel Dagnelund, Simon Sanden, Slawomir Braun, Harri Aarnio, Xianjie Liu, Weimin Chen, Ronald Osterbacka and Mats Fahlman

\section{Linköping University Post Print}

\section{Tweet}

N.B.: When citing this work, cite the original article.

Original Publication:

Qinye Bao, Oskar Sandberg, Daniel Dagnelund, Simon Sanden, Slawomir Braun, Harri Aarnio, Xianjie Liu, Weimin Chen, Ronald Osterbacka and Mats Fahlman, Trap-Assisted Recombination via Integer Charge Transfer States in Organic Bulk Heterojunction Photovoltaics, 2014, Advanced Functional Materials, (24), 40, 6309-6316.

http://dx.doi.org/10.1002/adfm.201401513

Copyright: Wiley-VCH Verlag http://www.wiley-vch.de/publish/en/

Postprint available at: Linköping University Electronic Press http://urn.kb.se/resolve?urn=urn:nbn:se:liu:diva-112635 


\section{Article type: Full paper}

Trap-assisted recombination via integer charge transfer states in organic bulk heterojunction photovoltaics

Qinye Bao,* Oskar Sandberg, Daniel Dagnelund, Simon Sandén, Slawomir Braun, Harri Aarnio, Xianjie Liu, Weimin M. Chen, Ronald Österbacka and Mats Fahlman*

Q. Bao, Dr. S. Braun, Dr. X. Liu and Prof. M. Fahlman

Division of Surface Physics and Chemistry, Department of Physics, Chemistry and Biology, Linköping University, SE-58183 Linköping, Sweden.

E-mail: qinba@ifm.liu.se, mats.fahlman@liu.se

Dr. O. Sandberg, Dr. S. Sandén, Dr. H. Aarnio and Prof. R. Österbacka Center for Functional Materials, Department for Natural Sciences, Åbo Akademi University, FI-20500 Turku, Finland

Dr. D. Dagnelund and Prof. W. Chen Division of Functional Electronic Materials, Department of Physics, Chemistry and Biology, Linköping University, SE-58183 Linköping, Sweden

Keywords: pinning energy, trap-assisted recombination, interface, open circuit voltage, organic solar cell

Abstract: Organic photovoltaic is under intense development and significant focus has been placed on tuning the donor ionization potential and acceptor electron affinity to optimize open circuit voltage. Here we show that for a series of regioregular-poly(3hexylthiophene):fullerene bulk heterojunction organic photovoltaic devices with pinned electrodes, integer charge transfer states present in the dark and created as a consequence of Fermi level equilibrium at BHJ have a profound effect on open circuit voltage. The integer charge transfer state formation causes vacuum level misalignment that yields a roughly constant effective donor ionization potential to acceptor electron affinity energy difference at the donor-acceptor interface, even though there is a large variation in electron affinity for 
the fullerene series. The large variation in open circuit voltage for the corresponding device series instead is found to be a consequence of trap-assisted recombination via integer charge transfer states. Based on the results, novel design rules for optimizing open circuit voltage and performance of organic bulk heterojunction solar cells are proposed.

\section{Introduction}

With the rapidly rising energy conversion efficiency of up to $10 \%,{ }^{[1,2]}$ organic photovoltaic (OPV) devices such as polymer:fullerene bulk heterojunction (BHJ) solar cells are considered to be a promising renewable-energy source with the potential of high throughput, low manufacturing cost, light weight and mechanical flexibility. ${ }^{[3,4]}$ In order to further optimize and improve the efficiencies so as to enable their successful commercialization, significant efforts are made to increase two particular photovoltaic parameters: short circuit current density $\left(J_{s c}\right)$ and open circuit voltage $\left(V_{o c}\right){ }^{[5-8]}$ The energy difference between the hole-transporting level of the donor and the electron-transporting level of the acceptor heavily influences the $V_{o c}$ and can be seen as an upper limit to what can be achieved in the device. Strategies to increase the $V_{o c}$ typically have focused on synthesis of new polymers and/or new acceptor/fullerene derivatives so as to achieve optimal Donor (D) - Acceptor (A) energy level offsets. ${ }^{[9-11]}$ More recently, a significant influence of photogenerated donor-acceptor charge transfer (CT) complexes on $V_{o c}$ has been demonstrated, ${ }^{[12,13]}$ but strategies for $V_{o c}$ (and overall efficiency) improvement based on this effect are less explored. In general, the $V_{o c}$ is found to be proportional to the 
incoming light intensity $I$ such that $e V_{o c} \propto n_{S} k T \ln (I)$, where $n_{S}$ is a prefactor (sometimes referred to as the light ideality factor), usually $1<n_{S}<2$. $^{[14]}$

Ultraviolet photoelectron spectroscopy (UPS), inverse photoemission spectroscopy (IPES) and cyclic voltammetry (CV) are typically used to measure the energies of the holeand electron transporting levels, with CV being most commonly used due to its relative simplicity and low cost. Knowledge of the (bulk) transport levels does not enable the determination of electrode and BHJ energetics, however, as a potential step is often formed at metal/organic and organic/organic interfaces modifying the relative position of the energy levels at either side of the interface, ${ }^{[15]}$ even for weakly-interacting physisorbed interfaces such as those typically found in a BHJ solar cell. ${ }^{[16-20]}$

It's proposed that the energy level alignment at weakly-interacting metal/organic and organic/organic interfaces and in multilayer stacks can be predicted by the Integer Charge Transfer (ICT) model ${ }^{[16,21,22]}$ where the relation between the original Fermi level of a surface and the so-called pinning energies $\left(\mathrm{E}_{\mathrm{ICT}+,-}\right)$ of the organic semiconductor (OS) overlayer plays a key role. The $\mathrm{E}_{\mathrm{ICT}+}\left(\mathrm{E}_{\mathrm{ICT}-\text { ) }}\right.$ energy of the positive (negative) ICT state relates to the smallest energy required to take away one electron (the largest energy gained from adding one electron) from (to) the OS molecule at an interface producing a fully relaxed state, where screening from the environment and the Coulombic interaction with the opposite charge across the interface are included. ${ }^{[23]}$ These energies hence are related to but differ from the bulk ionization potential (IP) and electron affinity (EA) of the OS, i.e. the polaronic transport states, see Fig. S1 in the supplementary information and described in more detail elsewhere. ${ }^{[17,23-25]}$ Here we stress that the $\mathrm{E}_{\mathrm{ICT}+}\left(\mathrm{E}_{\mathrm{ICT}-}\right)$ are located further 
into the gap compared to the free bulk polarons of the material, as the positive and negative polarons formed in the ICT-process are coulombically bound at the interface by the opposing charge. We also stress that the ICT states are formed spontaneously to equilibrate the Fermi level at a heterojunction and are thus not photogenerated.

The pinning energies, also accessible by density functional theory, ${ }^{[24]}$ can be applied to determine the energetics at the various interfaces in a BHJ solar cell and the possible existence of ICT states formed by spontaneous charge transfer at the BHJ interface, ${ }^{[17]}$ the latter which can enhance the transformation of excitons into free charge carriers at the (bulk) heterojunction. ${ }^{[26,27]}$ The effect, if any, of ICT states on $V_{o c}$ has yet to be explored, however.

In polymer:fullerene $\mathrm{BHJ}$ solar cells, because the archetypical fullerenes $\mathrm{C}_{60} / \mathrm{C}_{70}$ themselves are prone to aggregation and difficult to process with polymer donors, the monoadduct fullerene derivatives $\mathrm{PC}_{60} \mathrm{BM}$ and $\mathrm{PC}_{70} \mathrm{BM}$ widely dominate in terms of choice of acceptor material. ${ }^{[4,7,28,29]}$ Recently, other fullerene derivatives with multiadducts with smaller EA energies have been introduced in BHJ device to increase the donor IP acceptor EA energy difference and thereby enhance output performance by raising $V_{o c}{ }^{[30-32]}$ In this paper, we use UPS to systematically map out the occupied electronic structure and universal pinning energies of a series of fullerenes: $\mathrm{C}_{60} / 70, \mathrm{PC}_{60 / 70} \mathrm{BM}, \mathrm{BisPC}_{60} \mathrm{BM}$, TrisPC ${ }_{60} \mathrm{BM}$ and $\mathrm{IC}_{60} \mathrm{BA}$. The formation of ICT states at rr-P3HT:fullerene $\mathrm{BHJ}$ is addressed and the effect on $V_{\mathrm{oc}}$ is commented upon using modelling and device data from literature. In Fig. S2 the chemical structure and in Fig. S3 the frontier occupied electronic structure of fullerene and its derivatives considered in this study are exhibited (see supplementary information). 


\section{Results and Discussion}

Fig. 1a displays the dependences of the work function of fullerene-coated substrates, $\Phi_{\text {org/sub }}$, on the work function of the original bare substrates, $\Phi_{\text {sub }}$. Two distinct slope $S=0$ regions are clearly observed, separated by an $\mathrm{S}=1$ region, as predicted by the ICT model. When the $\Phi_{\text {sub }}$ is smaller than the $\mathrm{E}_{\mathrm{ICT} \text { - }}$ of a particular fullerene derivative, electrons spontaneously tunnel from the substrate into the fullerene molecules until equilibrium is reached, causing the formation of a potential step and pinning the Fermi level to the negative integer charge transfer state. The $\mathrm{E}_{\mathrm{ICT}}$ - values corresponding to $\mathrm{C}_{60}, \mathrm{C}_{70}, \mathrm{PC}_{60} \mathrm{BM}$, $\mathrm{PC}_{70} \mathrm{BM}$ bisPC ${ }_{60} \mathrm{BM}$, trisPC ${ }_{60} \mathrm{BM}$ and $\mathrm{IC}_{60} \mathrm{BA}$ fullerenes are $4.57,4.65,4.31,4.35,4.12$, 3.95 and $4.05 \mathrm{eV}$, respectively, as derived from Fig. 1a. For $\Phi_{\text {sub }}$ greater than the $\mathrm{E}_{\mathrm{ICT}+}$, spontaneous electron transfer occurs from the fullerene molecules to the substrate, creating a potential step that downshifts the vacuum level and the Fermi level is pinned to the positive integer charge transfer state of the fullerene. The $\mathrm{E}_{\mathrm{ICT}+}$ values of the fullerene derivatives are estimated from Fig. 1a as 5.55, 5.48, 5.32, 5.22, 5.08, 4.95 and $5.15 \mathrm{eV}$, respectively. In the transition region $(S=1)$ between the negative and positive pinning regime, the $\Phi_{\text {org/sub }}$ of fullerenes is equal to $\Phi_{\text {sub }}$, which means that no spontaneous charge transfer across interface and vacuum level (VL) alignment holds. For trisPC ${ }_{60} \mathrm{BM}$, there is a displacement in $\Phi_{\text {org/sub }}$ of $\sim 0.2 \mathrm{eV}$ away from the "ideal" VL alignment behavior as shown in Fig. 1a. We tentatively attribute the effect to preferential ordering of tris $\mathrm{PC}_{60} \mathrm{BM}$ molecules, see Fig. S5 and discussion in the supplementary information. Fig. 1b shows the evolution of the fullerene $\mathrm{E}_{\mathrm{ICT}+,-}$ with increasing number of adducts. For the different types of fullerene cages, the $\mathrm{E}_{\mathrm{ICT}}$ - values of $\mathrm{C}_{60} / \mathrm{PC}_{60} \mathrm{BM}$ are slightly smaller than that of the 
corresponding $\mathrm{C}_{70} / \mathrm{PC}_{70} \mathrm{BM}$ and the $\mathrm{E}_{\mathrm{ICT}+}$ slightly larger. The respective IP, EA and $\mathrm{E}_{\mathrm{ICT}+,-}$ for the fullerene series are listed in Table 1.

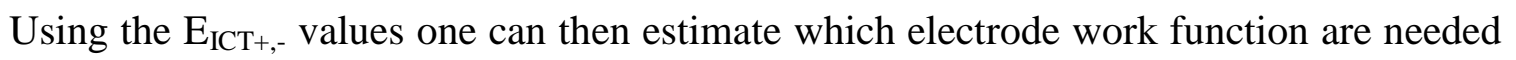
to pin the Fermi level at the respective contact, at which point the $V_{o c}$ is no longer limited by the work function difference of the electrodes: the anode work function should be equal or greater than the donor polymer $\mathrm{E}_{\mathrm{ICT}+}$ and the cathode work function equal or smaller than the fullerene $\mathrm{E}_{\mathrm{ICT} \text {. }}$ Typically PEDOT:PSS is used as the anode material and though the work function depends on the particular formulation it is often around $5.1 \mathrm{eV}^{[10]}$ significantly larger than the measured $\mathrm{E}_{\mathrm{ICT}+}$ of most of the donor polymers. The PEDOT:PSS interface thus is expected to feature Fermi level pinning to the donor polymer $\mathrm{E}_{\mathrm{ICT}+}$, as desired. At the cathode side, an electrode work function smaller than the acceptor fullerene $\mathrm{E}_{\mathrm{ICT}-}$ is needed to achieve a pinned interface. From the device characteristics of ITO/PEDOT:PSS/MDMO-PPV:PC ${ }_{60} \mathrm{BM} /$ cathode (LiF/Al, $\mathrm{Ag}, \mathrm{Au}$ and $\mathrm{Pd}$ ) reported by Mihailetchi, ${ }^{[33]}$ the dependence of $V_{o c}$ on different cathode work function has been explored and for $\mathrm{Ag}, \mathrm{Au}$ and Pd cathodes, there is a significant decrease in $V_{o c}$ obtained compared to the case of the low work function $\mathrm{LiF} / \mathrm{Al}$ contact that is pinned $(0.9 \mathrm{~V}$ for $\mathrm{LiF} / \mathrm{Al}$ down to $0.4 \mathrm{~V}$ for $\mathrm{Pd}$ ). Such a decrease is expected from our results as the $\mathrm{E}_{\mathrm{ICT}-}$ of $\mathrm{PC}_{60} \mathrm{BM}$ is $\sim 4.3$ $\mathrm{eV}$ and the higher work function $\mathrm{Ag}$, Au or Pd hence will not provide a pinned contact, unlike $\mathrm{LiF} / \mathrm{Al}$ whose (process-dependent) work function is $\sim 3.6 \mathrm{eV}$ or lower. ${ }^{[34]}$

For the case of pinned electrode contacts, the $V_{o c}$ is suggested to be controlled by the donor/acceptor blend, though recent literature makes clear that donor IP - acceptor EA energy difference $\left(\Delta E_{g}^{D A}\right)$ alone does not adequately describe the $V_{o c}{ }^{[12,13]}$ The influence of 
the D/A blend properties, including the effects from ICT states (if any), thus can be explored using data from ITO/PEDOT:PSS/rr-P3HT:fullerene $\left(\mathrm{C}_{60}, \mathrm{C}_{70}, \mathrm{PC}_{60} \mathrm{BM}, \mathrm{PC}_{70} \mathrm{BM}\right.$, bis $\mathrm{PC}_{60} \mathrm{BM}$, trisPC ${ }_{60} \mathrm{BM}$ and $\left.\mathrm{IC}_{60} \mathrm{BA}\right) / \mathrm{LiF} / \mathrm{Al}$ devices, where the $\mathrm{LiF} / \mathrm{Al}$ cathode will pin to the $\mathrm{E}_{\mathrm{ICT}}$ of all fullerenes we studied here and the PEDOT:PSS anode will likewise pin to the $\mathrm{E}_{\mathrm{ICT}+}$ of rr-P3HT, $4.0 \mathrm{eV} .^{[26]}$

We first look at the effect of ICT states at the BHJ that according to the ICT model may form to ensure Fermi level equilibrium at interfaces. Inserting an intrinsic dipole layer at a donor-acceptor junction forming a trilayer will increase the effective $\mathrm{IP}_{\mathrm{D}}-\mathrm{EA}_{\mathrm{A}}$ difference $\left(\Delta E_{g, e f f}^{D A}\right)$ and hence the $V_{o c}$ for the case of a dipole layer with the negative side at the acceptor and decrease the $\Delta E_{g, \text { eff }}^{D A}\left(\right.$ and hence the $V_{o c}$ ) for the case of a dipole layer with the negative side at the donor, see Fig. S6a and $b$ in supplementary information. ${ }^{[35]}$ The effect on $V_{o c}$ is different if the dipole shift is introduced through the formation of ICT states as per the ICT model (see supplementary background), however, as we will show using $V_{o c}$ values from the ITO/PEDOT:PSS/rr-P3HT:fullerene/LiF/Al device series, the corresponding donor IP ( 4.6 eV for rr-P3HT) and (fullerene) acceptor EA values as well as BHJ potential steps derived from the $\mathrm{E}_{\mathrm{ICT}+,-}$ values, see Table 1.

As is evident from Table 1, failing to account for vacuum level misalignment at the BHJ (interface potential steps) can produce severe errors in the estimation of the effective $\Delta E_{g}^{D A}$, i.e. $\Delta E_{g, e f f}^{D A}$ in Table 1, as for some fullerene:rr-P3HT combinations there is a large interface potential step. Note also that for this particular series, the $V_{o c}$ seems largely independent of the $\Delta E_{g, e f f}^{D A}$ values (the two lowest $\Delta E_{g, e f f}^{D A}$ actually produces the two highest $V_{o c}$ ). Furthermore, 
the $\Delta E_{g, \text { eff }}^{D A}$ values show only a small variation $(\sim 1.1-1.25 \mathrm{eV})$ despite the large variation in (bulk) donor IP - acceptor EA energies $\left(\Delta E_{g}^{D A}\right)$, as a decrease in acceptor EA also causes a decrease in acceptor $\mathrm{E}_{\mathrm{ICT} \text { - }}$ and thus a decrease in the $\Delta$. Modifying the fullerene EA in regards to a particular donor IP (or modifying a donor IP in regards to a particular fullerene EA) hence is not expected to significantly change $\Delta E_{g, \text { eff }}^{D A}$ as long as the BHJ is in the pinned regime (the case for the rr-P3HT series, with the exception of trisPC ${ }_{60} \mathrm{BM}$, though the 0.05 $\mathrm{eV}$ difference between the $\mathrm{E}_{\mathrm{ICT}+,-}$ levels are within the error margin of the measurement). This obviously also holds true for the effective donor EA - acceptor EA relation $\left(\Delta E_{g, e f f}^{D A}\right.$. The increase in $V_{o c}$ obtained by introducing fullerene derivatives with multiadducts with smaller EA energies hence does not increase the effective donor IP - acceptor EA energy difference unlike previously believed ${ }^{[30-32]}$ and the cause for the enhanced $V_{o c}$ must be found elsewhere.

To better understand the processes that influence on $V_{o c}$, we build upon recent models that assume direct bimolecular recombination between free charge carriers to obtain the following expression (analysis based on a pn-junction approach is given in the supplementary information) ${ }^{[14,36]}$ :

$e V_{o c}=\Delta E_{g, e f f}^{D A}-k T \ln \left(\frac{\beta N_{c} N_{v}}{G}\right)=\Delta E_{g}^{D A}+\Delta-k T \ln \left(\frac{\beta N_{c} N_{v}}{G}\right)$

where $\Delta E_{g}^{D A}$ is as noted the difference between the IP of the donor and the EA of the acceptor before junction formation, $\Delta$ is a factor that accounts for effects such as vacuum level misalignments at the BHJ that modify the activation energy gained from $\Delta E_{g}^{D A}$, $\Delta E_{g, e f f}^{D A}=\Delta E_{g}^{D A}+\Delta$ is then the effective energy gap between the donor IP and acceptor 
EA taking into account vacuum level misalignment, and $N_{c}$ and $N_{v}$ are the effective density of transport (polaron) states, and $\beta$ is the bimolecular recombination coefficient. ${ }^{[37]}$ The free polaron generation rate $G$, is usually related to the light intensity as $G \propto I^{\alpha}$, where $\alpha$ is close to unity. The probability for CT complexes, formed upon direct recombination between free carriers (polarons), to dissociate back to free carriers has been effectively included in the bimolecular recombination coefficient $\beta$. It can be shown that Eq. 1 is equivalent to the more commonly used formula:

$e V_{o c}=k T \ln \left(\frac{J_{s c}}{J_{0}}+1\right)$

where $J_{s c}$ is the short-circuit current density and $J_{0}$ is reverse dark saturation current density (see supplementary information).

If a large amount of recombination centers or trapped carriers exist, trap-assisted recombination may also occur at the D/A BHJ interface, which further modifies Eq. 1. This process is usually taken to follow Shockley-Read-Hall (SRH) recombination and has in rrP3HT:PC 60 BM OPVs been attributed to involve localized states in the tails of the rr-P3HT valence band and $\mathrm{PC}_{60} \mathrm{BM}$ conduction band acting as traps and consequently recombination sites $^{[38]}$. Trap-assisted recombination via occupied ICT states, if present, will also occur as the donor $\mathrm{E}_{\mathrm{ICT}+}$ is situated above the free positive polaron and the acceptor $\mathrm{E}_{\mathrm{ICT}-}$ is situated below the free negative polaron, ${ }^{[16,23,24]}$ see Fig. 2 . If ICT states have been created as per the ICT model, a free negative (positive) polaron in the fullerene (polymer) thus may recombine with a $E_{I C T+}\left(E_{I C T \text { - }}\right)$ related positive (negative) polaron located at the interface in the polymer (fullerene) as illustrated in Fig. 2. If trap-assisted recombination via these 
states becomes comparable to the direct bimolecular recombination one finds (see supplementary information section 2.5):

$e V_{o c}=\Delta E_{g, e f f}^{D A}-k T \ln \left(\frac{\beta N_{c} N_{v}+\beta_{S R H} N_{I C T} \sqrt{N_{c} N_{v}} \exp \left(\frac{\Delta E_{g, e f f^{-e V o c}}^{D A}}{2 k T}\right)}{G}\right) \approx \Delta E_{g, e f f}^{D A}-$ $n_{S} k T \ln \left(\frac{C_{0}(\Delta)}{G}\right) \quad$ (Eq. 3)

where $N_{I C T}$ is the density of ICT states and $C_{0}$ is a function of $\Delta$. As all recombination essentially occur at the interfaces, in case of a large amount of ICT states trap-assisted recombination via these states is expected. The prefactor $n_{S}$ increases with increasing trapassisted recombination and is thus related to the dominating recombination process, the two extreme cases being $n_{S}=1$ for direct bimolecular recombination and $n_{S}=2$ for trapassisted recombination. To a first approximation: $\frac{\Delta}{q} \sim \frac{q N_{I C T}}{\epsilon \epsilon_{0}} \delta^{2}$, where $\delta$ is the dipole thickness. Consequently, if the dipole $\Delta$ is large, $\mathrm{N}_{\text {ICT }}$ also is large and the trap-assisted recombination is expected to be more prominent.

The existence of ICT states at the D/A interface occur when $\mathrm{E}_{\mathrm{ICT}+, \mathrm{D}} \leq \mathrm{E}_{\mathrm{ICT}-, \mathrm{A}}$ and ICT states act as sites for recombination that reduce the $\mathrm{V}_{\mathrm{oc}}$. On the other hand, previous studies suggests that the generation of free charges at the D/A interface is enhanced by the type of interface dipole generated by the ICT states. ${ }^{[26,27]}$ Furthermore, the ICT states will populate the most easily oxidized polymer chains or chain segments on the rr-P3HT side of the heterojunction (most likely to undergo structural relaxation), and the most easily reduced $\mathrm{PC}_{60} \mathrm{BM}$ molecules at the other side (see supplementary information). In this way, the most 
tightly bound sites where charge transfer electron-hole pairs could be created at the interface are already occupied in the (dark) ground state and are consequently not available to participate in the exciton dissociation process following a photon absorption event, thus enhancing the percentage of excitons converted into free charges. ${ }^{[39,40]}$ Hence, there is likely a trade-off in terms of ICT state density as the presence of ICT states enhance the generation of free charges at the $\mathrm{BHJ}$, but also enhance the recombination of free charges at the BHJ. From the rr-P3HT:fullerene series studied here it seems that the sweet spot occurs for $\mathrm{E}_{\mathrm{ICT}-\mathrm{A}} \approx \mathrm{E}_{\mathrm{ICT}+, \mathrm{D}}\left(\right.$ e.g. $\left.\mathrm{rr}-\mathrm{P} 3 \mathrm{HT}: \mathrm{IC}_{60} \mathrm{BA}\right)$. We now test this hypothesis by measuring the $\mathrm{E}_{\mathrm{ICT}+}$ and IP of a set of high-performing donor polymers in literature and comparing the $\Delta E_{g, e f f}^{D A}$ with measured $\mathrm{V}_{\mathrm{oc}}$ from literature, see Fig. 3, Fig. S4 and Table S1. Striking in Fig. 3 is that many of the high performing polymer:fullerene blends precisely fall in the region (green in top panel of Fig. 3) where $\mathrm{E}_{\mathrm{ICT}-\mathrm{A}, \mathrm{A}}=\mathrm{E}_{\mathrm{ICT}+, \mathrm{D}} \pm 0.05 \mathrm{eV}$ and where the $\mathrm{V}_{\text {oc loss }}$ defined as the deviation from the ideal $\mathrm{V}_{\mathrm{oc}}\left(\Delta E_{g, e f f}^{D A}\right)$ in the measured $\mathrm{V}_{\mathrm{oc}}\left(e V_{\text {oc loss }}=\right.$ $\left.\Delta E_{g, e f f}^{D A}-e V_{o c}\right)$ is at its minimum, in agreement with our design rule. Note also that just a small deviation in either direction cause a significant jump in $\mathrm{V}_{\text {oc loss. }}$.

In terms of Eq. 1 and Eq. 3, $\mathrm{V}_{\text {oc loss }}$ can be rewritten as

$e V_{\text {oc loss }}=\left\{\begin{array}{l}k T \ln \left(\frac{\beta N_{C} N_{v}}{G}\right), \text { when } E_{I C T-, A}-E_{I C T+, D}<0 \\ n_{S} k T \ln \left(\frac{C_{0}(\Delta)}{G}\right), \text { when } E_{I C T-, A}-E_{I C T+, D}>0\end{array}\right.$

To the right of the green region in Fig. 3 there is no (dark) integer charge transfer at the bulk heterojunction $\left(\mathrm{E}_{\mathrm{ICT}+, \mathrm{D}}>\mathrm{E}_{\mathrm{ICT}-\mathrm{A}}\right.$ and $\left.\Delta=0\right)$. Consequently, no trap-assisted recombination via ICT states is expected and the dominating recombination process is 
bimolecular $\left(n_{S}=1\right)$. As the deviation of the fraction $\mathrm{G} / \beta$ in these blends is expected to be less than a factor of 1000 the deviation of $e V_{\text {oc loss }}$ is within $\sim 0.2 \mathrm{eV}$ in this region. When $\mathrm{E}_{\mathrm{ICT}+\mathrm{D}} \approx \mathrm{E}_{\mathrm{ICT}-\mathrm{A}}$ corresponding to the green region in Fig. 3 a decrease in $\mathrm{V}_{\mathrm{oc}}$ loss is seen. This can be explained in terms of an ICT-induced dipole layer that assists in the dissociation of photogenerated CT-complexes into free charges, ${ }^{[26,27,40]}$ leading to a dramatic increase of the fraction $\mathrm{G} / \beta$ in Eq. 1 .

To the left of the green region in Fig. 3, an increased difference between $\mathrm{E}_{\mathrm{ICT}+\mathrm{D}}$ and $\mathrm{E}_{\mathrm{ICT}-}$ ,A signifies an increased density of occupied ICT states (and interface potential step) at the bulk heterojunction interfaces that according to Eq. 3 and Eq. 4 cause an increased $V_{\text {oc loss }}$ due to the increased trap-assisted recombination $\left(\mathrm{n}_{\mathrm{S}}>1\right)$, which indeed is experimentally verified. Experimentally-derived prefactors $n_{S}$ obtained from literature are also shown in bottom panel of Fig. 3. An increasing trend for $n_{S}$ is found for blends with increasing $\Delta$, while for blends with $\Delta=0$ (to the right of the green region in Fig. 3) bimolecular recombination, or $n_{S}=1$, is found, in agreement with the model.

If our model holds, we expect the generation of ICT states when $\mathrm{E}_{\mathrm{ICT}+\mathrm{D}} \leq \mathrm{E}_{\mathrm{ICT}-\mathrm{A} \text {. }}$. Photoinduced absorption (PA) measurements show that in rr-P3HT:PC ${ }_{60} \mathrm{BM}$ where $\mathrm{E}_{\mathrm{ICT}+\mathrm{D}}$

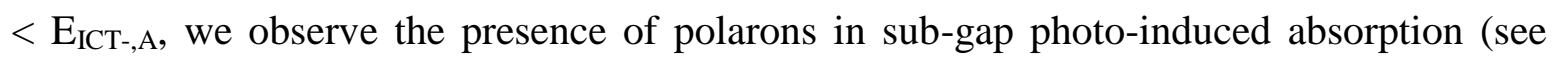
supplementary information Fig. S7a). The presence of polarons in the sub-gap photoinduced absorption could either be due to ICT states or photogenerated CT states, however. Furthermore, we could expect a small density of ICT states at the bulk heterojunction for the $\mathrm{D} / \mathrm{A}$ blends that feature $\mathrm{E}_{\mathrm{ICT}-\mathrm{A}} \approx \mathrm{E}_{\mathrm{ICT}+, \mathrm{D}}$ as the absolute frontier of the respective ICT distributions may overlap. To be able to probe such small levels of ICT density and exclude 
contribution from photogenerated CT states we turn to electron paramagnetic resonance (EPR) measurements carried out in the dark. We choose here $\mathrm{TQ1}: \mathrm{PC}_{70} \mathrm{BM}$ and TQ1:PC ${ }_{60} \mathrm{BM}$ blends (TQ1: poly[2,3-bis-(3-octyloxyphenyl)quinoxaline-5, 8-dilyl-altthiophene-2, 5-diyl]), as $\mathrm{E}_{\mathrm{ICT}-\mathrm{A}} \approx \mathrm{E}_{\mathrm{ICT}+, \mathrm{D}}$ for these donor-acceptor combinations and due to the high purity of TQ1 as compared to rr-P3HT (see section 2.4 of the supplementary information). TQ1 is a donor polymer featuring comparatively high $\mathrm{V}_{\mathrm{oc}}(0.89 \mathrm{~V})$ and power conversion efficiencies $(6 \%)$ when used in combination with $\mathrm{PC}_{70} \mathrm{BM}^{[41]}$ Since $\mathrm{E}_{\mathrm{ICT}-\mathrm{A}} \approx$ $\mathrm{E}_{\mathrm{ICT}+\mathrm{D}}$ there is no dipole at the D/A interfaces as measured by UPS. However, as the frontier edge of the respective ICT distributions likely will overlap, some integer charge transfer is still expected involving the most easily oxidized sites of the donor polymers and most easily reduced sites on the fullerene side of the heterojunction (see Fig. S1 and the related discussion in the supplementary information). The neat films of $\mathrm{PC}_{60} \mathrm{BM}, \mathrm{PC}_{70} \mathrm{BM}$ and TQ1 all show weak signals related to spin-carrying species, see Fig. 4 and Fig. S8 for further details. The $\mathrm{TQ1}: \mathrm{PC}_{70} \mathrm{BM}$ and $\mathrm{TQ1}: \mathrm{PC}_{60} \mathrm{BM}$ blends, however, feature new and significantly stronger EPR signals with g-factors and linewidths that are different from those of the neat films (see Fig. S8). These new EPR signals are most easily seen by subtracting the individual contributions of TQ1 and the respective fullerene from the blend EPR spectra, see the lowest curves in Fig. $4 a$ and b. The appearance of such strong new EPR signals demonstrate that new spin-carrying species (polarons) are formed through integer charge transfer in the dark at the heterojunctions, i.e. the formation of ICT states as predicted by the ICT model. 
Thus a set of new design criteria using measured or calculated ICT states for BHJ solar cells can be proposed:

(i) Pinned electrode contacts are obtained by: $\Phi_{\text {anode }} \geq \mathrm{E}_{\mathrm{ICT}+, \mathrm{D}}$ and $\Phi_{\text {cathode }} \leq \mathrm{E}_{\mathrm{ICT}-\mathrm{A}}$

(ii) Donor:acceptor combinations should be chosen so that $\mathrm{E}_{\mathrm{ICT}-\mathrm{A}} \approx \mathrm{E}_{\mathrm{ICT}+, \mathrm{D}}$

\section{Conclusion}

We have studied that for a series of regioregular-poly(3-hexylthiophene):fullerene bulk heterojunction organic photovoltaic devices with pinned electrodes, integer charge transfer states present in the dark and created as a consequence of Fermi level equilibrium at BHJ have a profound effect on open circuit voltage. The donor ionization potential to acceptor electron affinity energy difference is thought to provide an upper limit to the $\mathrm{V}_{\mathrm{oc}}$ in bulk heterojunction solar cells, but it is the effective energy gap including possible potential steps at the bulk heterojunction that is the relevant parameter. Here, the ICT state formation cause vacuum level misalignment that yields a roughly constant effective donor ionization potential to acceptor electron affinity energy difference at the donor-acceptor interface, even though there is a large variation in the fullerene series' electron affinity. We find that the large variation in open circuit voltage for the device series featuring different fullerenes instead is found to be a consequence of variations in trap-assisted recombination via ICT states, and show that this holds true regardless if one assumes a metal-insulator-metal or pn-junction based description of bulk heterojunction solar cells. EPR measurements confirm the creation of ICT states at the bulk heterojunctions in the dark and together with PA measurements show that the D/A coupling strength and recombination-induced loss can 
be estimated using the so-called pinning energies $\left(\mathrm{E}_{\mathrm{ICT}+,-}\right)$. The results enable us to propose novel design rules for the donor/acceptor materials that hold the promise of in silico design of materials, as the these properties also can be calculated by e.g. DFT-based methods: (i)

Pinned electrode contacts are obtained by: $\Phi_{\text {anode }} \geq \mathrm{E}_{\mathrm{ICT}+, \mathrm{D}}$ and $\Phi_{\text {cathode }} \leq \mathrm{E}_{\mathrm{ICT}-\mathrm{A}}$, (ii) Donor:acceptor combinations should be chosen so that $\mathrm{E}_{\mathrm{ICT}-\mathrm{A}} \approx \mathrm{E}_{\mathrm{ICT}+\mathrm{D} \text {. The design rules }}$ are tested against a series of high performing donor polymers and their corresponding fullerene-based OPV devices available in literature, and excellent correlation is obtained.

\section{Experiment Section}

The fullerenes $\mathrm{C}_{60 / 70}$ were obtained from Sigma Aldrich, and its derivatives $\mathrm{PC}_{60 / 70} \mathrm{BM}$, $\mathrm{Bis}_{60} \mathrm{BM}$, tris $\mathrm{PC}_{60} \mathrm{BM}$ and $\mathrm{IC}_{60} \mathrm{BA}$ were purchased from Solenne BV. Polymer rr-P3HT was obtained from Sigma Aldrich, and PCPDTBT and PBDTTT-CF from One-Material. TQ1, P(2)-FQ-BDT-4TR, PFQBDT-TR1, PBDTA-MIM and APFO3 were synthesized at Chalmers University of Technology. All films were spin-coated from o-dichlorobenzene solutions and fabricated in a clean room, then directly transferred using a container covered with aluminum foil to shield from illuminations, into the load lock chamber of the ultrahigh vacuum (UHV) system used for measurement. Sets of conductive substrates were chose to provide a broad range of the work function: AlOx/Al dipped with NH3 solution 3.6-3.8 $\mathrm{eV}, \mathrm{ZnO}$ nanoparticle film coated ITO 3.7-3.9 eV, AlOx/Al 3.8-4.0 eV, $\mathrm{SiOx} / \mathrm{Si} \sim 4.2-$ $4.4 \mathrm{eV}, \mathrm{AuOx} / \mathrm{Au} \sim 4.3-4.7 \mathrm{eV}, \mathrm{CuOx} / \mathrm{Cu} \sim 4.4-4.5 \mathrm{eV}, \mathrm{AgOx} / \mathrm{Ag} \sim 4.5-4.6 \mathrm{eV}, \mathrm{ITO}$ and UVO treatment 4.6-4.9 eV, PEDOT:PSS 5.0-5.2 eV, and UVO treated AuOx/Au 5.3- 
$5.9 \mathrm{eV}$. All substrates were cleaned by sonication in acetone and isopropyl before spin coating.

Ultraviolet photoelectron spectroscopy (UPS): UPS measurements were performed in an UHV surface analysis system including a sample analysis chamber with the base pressure of $\sim 2 \times 10^{-10}$ mbar to characterize the work function of the substrates and fullerene films coated different substrates, respectively. UPS with $\mathrm{HeI} 21.22 \mathrm{eV}$ as the excitation source was recorded with a Scienta-200 hemispherical analyzer, and calibrated by determining Fermi level edge of the Ar+ ion sputter-cleaned Au foil. The work function is derived from the secondary electron cut-off and the vertical ionization potential (IP) from the frontier edge of the occupied density of states.

Near edge $x$-ray adsorption fine structure (NEXAFS): NEXAFS spectra were performed at beam line D1011 of the MAX-II storage ring at the MAX lab, Sweden. The energy resolution was about $100 \mathrm{meV}$ at photon energy close to the $\mathrm{C} \mathrm{K}$ edge. NEXAFS spectra were collected in the partial electron yield mode by MCP with a different negative bias to screen the electrons with lower kinetic energy.

Photo-induced absorption (PA): Samples for photo-induced absorption experiments were prepared from $25 \mathrm{mg} / \mathrm{ml}$ chlorobenzene solutions of polymers including regioregular poly(3-hexylthiophene) and TQ1 mixed with fullerene $\left(\mathrm{PC}_{60} \mathrm{BM}, \mathrm{PC}_{70} \mathrm{BM}, \mathrm{IC}_{60} \mathrm{BA}\right)$ in 1:1 ratio by weight, by spincoating on sapphire substrates. Sample preparations were carried out in Nitrogen atmosphere. Annealing of the samples was performed on a hotplate at $120{ }^{\circ} \mathrm{C}$ for 15 minutes in Nitrogen atmosphere. For measurements, the sample was 
transferred to a cryostat (Janis Research), where it was kept under vacuum at room temperature (300 K). Photo-induced absorption was measured using either an Argon ion laser (Coherent Innova) for $514 \mathrm{~nm}(2.41 \mathrm{eV})$ excitation light (above-gap), or a diode laser (Power Technology) for $785 \mathrm{~nm}(1.58 \mathrm{eV})$ excitation light (below-gap). Both were set to an excitation intensity of $180 \mathrm{~mW} / \mathrm{cm}^{2}$. The excitation light was modulated by a mechanical chopper at $133 \mathrm{~Hz}$. A tungsten projector lamp with appropriate cutoff filters served as probe light, which, after passing through the sample, was directed through a monochromator (Acton Research Corporation) and detected with Si, Ge and liquid nitrogen cooled InSb detectors and a lock-in amplifier (Stanford Research).

Electron paramagnetic resonance $(E P R)$ : EPR experiments were performed using a Bruker Elexsys E500 spectrometer operating at $9.88 \mathrm{GHz}$ (X-band). All EPR spectra were obtained in dark and at room temperature. All blends were 1:1 by weight. All EPR spectra were normalized for film volume.

Additional information: Supporting Information is available from the Wiley Online Library or from the author

Acknowledgements: The work at Linköping University was sponsored by a project grant No 34142-1 from the Swedish Energy Agency and by the European Commission FP7 collaborative project SUNFLOWER (FP7-ICT-2011-7, Grant No. 287594). The work at Åbo Akademi University was supported in part by a project No.137093 (POHSC) from the Academy of Finland. X.L. and D.D. acknowledge support from The Swedish Research Council Linnaeus grant LiLi-NFM, while S.S. and R.Ö. acknowledge personal grants from 
the Waldemar von Frenckell Foundation and Swedish Cultural Foundation in Finland, respectively. S.B. acknowledges support from the Advanced Functional Materials Center at Linköping University.

Received: ((will be filled in by the editorial staff))

Revised: ((will be filled in by the editorial staff)) Published online: ((will be filled in by the editorial staff))

\section{References}

1. Z. C. He, C. M. Zhong, S. J. Su, M. Xu, H. B. Wu, and Y. Cao, Nat. Phot. 2012, 6, 591.

2. J. You, L. Dou, K. Yoshimura, T. Kato, K. Ohya, T. Moriarty, K. Emery, C. C. Chen, J. Gao, G. Li, and Y. Yang, Nat. Commun. 2013, 4, 1446.

3. M. Helgesen, R. Sondergaard, and F. C. Krebs, J. Mater. Chem. 2010, 20, 36.

4. H. Jin, C. Tao, M. Velusamy, M. Aljada, Y. L. Zhang, M. Hambsch, P. L. Burn, and P. Meredith, Adv. Mater. 2012, 24, 2572.

5. J. Jo, S. S. Kim, S. I. Na, B. K. Yu, and D. Y. Kim, Adv. Funct. Mater. 2009, 19, 866.

6. Z. C. He, C. M. Zhong, X. Huang, W. Y. Wong, H. B. Wu, L. W. Chen, S. J. Su, and Y. Cao, Adv. Mater. 2011, 23, 4636.

7. H. Y. Chen, J. H. Hou, S. Q. Zhang, Y. Y. Liang, G. W. Yang, Y. Yang, L. P. Yu, Y. Wu, and G. Li, Nat. Phot. 2009, 3, 649.

8. B. Yang, Y. B. Yuan, P. Sharma, S. Poddar, R. Korlacki, S. Ducharme, A. Gruverman, R. Saraf, and J. S. Huang, Adv. Mater. 2012, 24, 1455.

9. C. J. Brabec, A. Cravino, D. Meissner, N. S. Sariciftci, T. Fromherz, M. T. Rispens, L. Sanchez, and J. C. Hummelen, Adv. Funct. Mater. 2001, 11, 374.

10. B. Yang, F. W. Guo, Y. B. Yuan, Z. G. Xiao, Y. Z. Lu, Q. F. Dong, and J. S. Huang, Adv. Mater. 2013, 25, 572.

11. J. Y. Yuan, Z. C. Zhai, H. L. Dong, J. Li, Z. Q. Jiang, Y. Y. Li, and W. L. Ma, Adv. Funct. Mater 2013, 23, 885.

12. M. D. Perez, C. Borek, S. R. Forrest, and M. E. Thompson, J. Am. Chem. Soc. 2009, $131,9281$.

13. K. Vandewal, K. Tvingstedt, A. Gadisa, O. Inganas, and J. V. Manca, Phys. Rev. B 2010, 81,8 .

14. W. Tress, K. Leo, and M. Riede, Appl. Phys. Lett. 2013, 102, 163901.

15. H. Ishii, K. Sugiyama, E. Ito, and K. Seki, Adv. Mater. 1999, 11, 605.

16. S. Braun, W. R. Salaneck, and M. Fahlman, Adv. Mater. 2009, 21, 1450. 
17. M. Fahlman, P. Sehati, W. Osikowicz, S. Braun, M. P. de Jong, and G. Brocks, J. Electron Spectrosc. Relat. Phenom. 2013, 190, 33.

18. M. T. Greiner, M. G. Helander, W. M. Tang, Z. B. Wang, J. Qiu, and Z. H. Lu, Nat. Mater. 2011, 11, 76.

19. C. Tengstedt, W. Osikowicz, W. R. Salaneck, I. D. Parker, C.-H. Hsu, and M. Fahlman, Appl. Phys. Lett. 2006, 88, 053502.

20. L. Ley, Y. Smets, C. I. Pakes, and J. Ristein, Adv. Funct. Mater. 2013, 23, 794.

21. S. Braun, X. Liu, W. R. Salaneck, and M. Fahlman, Org. Electron. 2010, 11, 212.

22. G. Brocks, D. Cakir, M. Bokdam, M. P. de Jong, and M. Fahlman, Org. Electron. 2012, 13, 1793.

23. M. Fahlman, A. Crispin, X. Crispin, S. K. M. Henze, M. P. de Jong, W. Osikowicz, C. Tengstedt, and W. R. Salaneck, J. Phys. Condens. Matter Inst. Phys. J 2007, 19, 183202.

24. M. Bokdam, D. Cakir, and G. Brocks, Appl. Phys. Lett. 2011, 98, 113303.

25. D. Cakir, M. Bokdam, M. P. de Jong, M. Fahlman, and G. Brocks, Appl. Phys. Lett. 2012, 100, 203302.

26. H. Aarnio, P. Sehati, S. Braun, M. Nyman, M. P. de Jong, M. Fahlman, and R. Osterbacka, Adv. Energy. Mater. 2011, 1, 792.

27. V. I. Arkhipov, P. Heremans, and H. Bassler, Appl. Phys. Lett. 2003, 82, 4605.

28. B. C. Thompson and J. M. J. Frechet, Angew. Chem. Int. Ed. 2008, 47, 58.

29. G. Dennler, M. C. Scharber, and C. J. Brabec, Adv. Mater. 2009, 21, 1323.

30. M. A. Faist, P. E. Keivanidis, S. Foster, P. H. Wobkenberg, T. D. Anthopoulos, D. D. C. Bradley, J. R. Durrant, and J. Nelson, J. Polym. Sci. Part B Polym. Phys. 2011, 49, 45.

31. Y. J. He, H. Y. Chen, J. H. Hou, and Y. F. Li, J. Am. Chem. Soc. 2010, 132, 1377.

32. M. Lenes, G. J. A. H. Wetzelaer, F. B. Kooistra, S. C. Veenstra, J. C. Hummelen, and P. W. M. Blom, Adv. Mater. 2008, 20, 2116.

33. V. D. Mihailetchi, P. W. M. Blom, J. C. Hummelen, and M. T. Rispens, J. Appl. Phys. 2003, 94, 6849.

34. S. K. M. Jonsson, E. Carlegrim, F. Zhang, W. R. Salaneck, and M. Fahlman, Jpn. J. Appl. Phys. 2005, 44, 3695.

35. A. Tada, Y. F. Geng, Q. S. Wei, K. Hashimoto, and K. Tajima, Nat. Mater. 2011, $10,450$.

36. L. J. A. Koster, E. C. P. Smits, V. D. Mihailetchi, and P. W. M. Blom, Phys. Rev. B 2005, 72, 085205 .

37. A. Pivrikas, N. S. Sariciftci, G. Juška, and R. Österbacka, Prog. Photovolt: Res. Appl. 2007, 15, 677.

38. T. Kirchartz, B. E. Pieters, J. Kirkpatrick, U. Rau, and J. Nelson, Phys. Rev. B 2011, 83, 115209.

39. F. Deschler, E. D. Como, T. Limmer, R. Tautz, T. Godde, M. Bayer, E. v. Hauff, S. Yilmaz, S. Allard, U. Scherf, and J. Feldmann, Phys. Rev. Lett. 2011, 107, 127402.

40. P. Sehati, S. Braun, L. Lindell, X. J. Liu, L. M. Andersson, and M. Fahlman, IEEE J. Sel. Top. Quantum Electron. 2010, 16, 1718. 
41. E. G. Wang, L. T. Hou, Z. Q. Wang, S. Hellstrom, F. L. Zhang, O. Inganas, and M. R. Andersson, Adv. Mater. 2010, 22, 5240.

42. G. A. H. Wetzelaer, M. Kuik, M. Lenes, and P. W. M. Blom, Appl. Phys. Lett. 2011, 99, 153506.

43. M. Nyman, personal communication.

44. L. M. Andersson, A. Melianas, Y. Infahasaeng, Z. Tang, A. Yartsev, O. Inganäs, and V. Sundström, J. Phys. Chem. Lett. 2013, 4, 2069.

45. L. J. A. Koster, V. D. Mihailetchi, R. Ramaker, and P. W. M. Blom, Appl. Phys. Lett. 2005, 86, 123509.

46. T. Tromholt, M. V. Madsen, and F. C. Krebs, Appl. Phys. Lett. 2013, 102, 123904.

47. Z. L. Guan, J. B. Kim, H. Wang, C. Jaye, D. A. Fischer, Y. L. Loo, and A. Kahn, Org. Electron. 2010, 11, 1779.

48. H. Li and J. Z. Wang, Appl. Phys. Lett. 2012, 101, 263901.

49. J. M. Ball, R. K. M. Bouwer, F. B. Kooistra, J. M. Frost, Y. B. Qi, E. B. Domingo, J. Smith, D. M. de Leeuw, J. C. Hummelen, J. Nelson, A. Kahn, N. Stingelin, D. D. C. Bradley, and T. D. Anthopoulos, J. Appl. Phys. 2011, 110, 014506.

50. H. Ohkita and S. Ito, Polymer 2011, 52, 4397.

51. Z.-L. Guan, J. Bok Kim, Y.-L. Loo, and A. Kahn, J. Appl. Phys. 2011, 110, 043719.

52. G. Q. Ren, C. W. Schlenker, E. Ahmed, S. Subramaniyan, S. Olthof, A. Kahn, D. S. Ginger, and S. A. Jenekhe, Adv. Funct. Mater. 2013, 23, 1238.

53. K. Akaike, K. Kanai, H. Yoshida, J. y. Tsutsumi, T. Nishi, N. Sato, Y. Ouchi, and K. Seki, J. Appl. Phys. 2008, 104, 023710.

54. K. Kanai, K. Akaike, K. Koyasu, K. Sakai, T. Nishi, Y. Kamizuru, T. Nishi, Y. Ouchi, and K. Seki, Appl. Phys. 2009, 95, 309.

55. Y. Yang, F. Arias, L. Echegoyen, S. Flanagan, A. Robertson, and L. J. Wilson, Proc. Electrochem. Soc. 1995, 95-10, 306. 
Figure and Table:
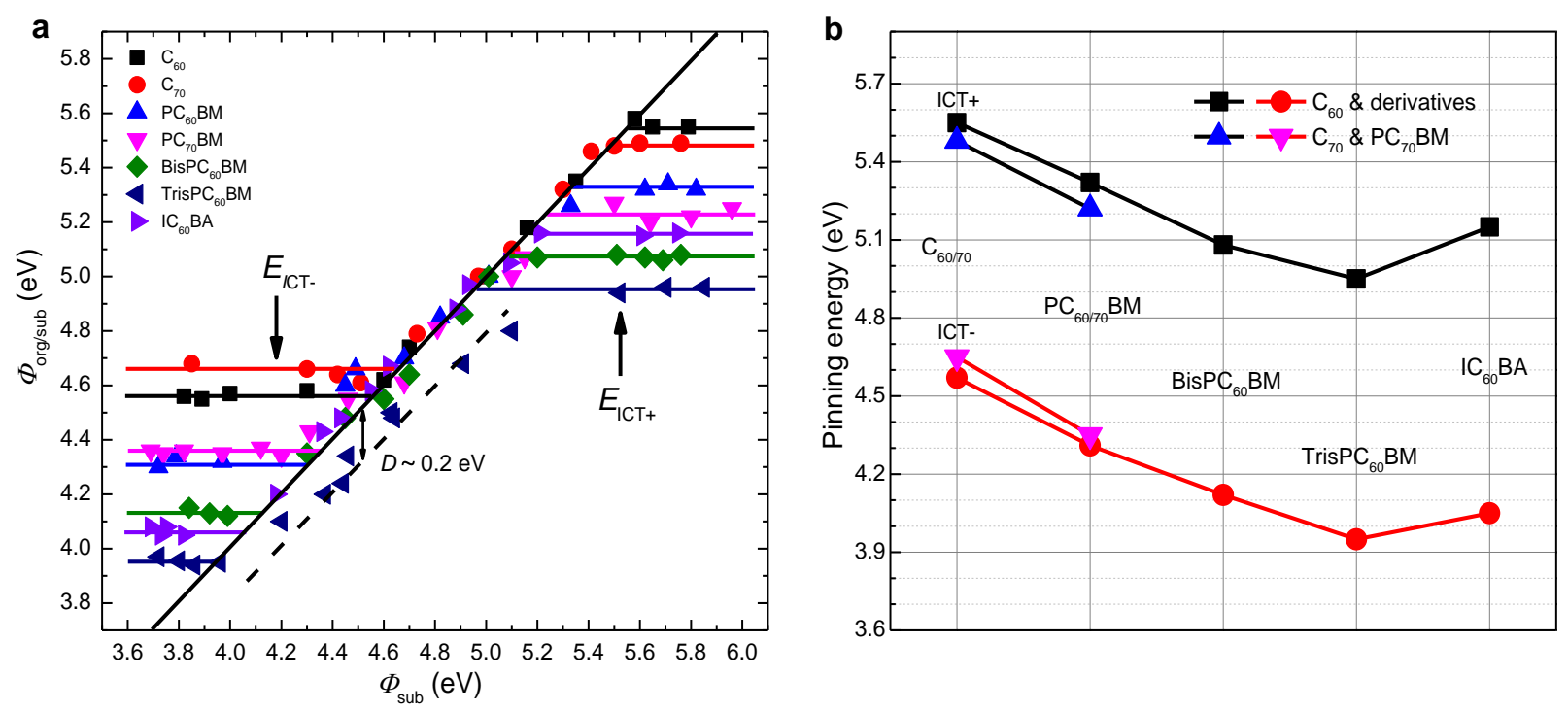

Figure 1. Universal pinning energies of a series of fullerenes. (a) Dependences of the work function of $\mathrm{C}_{60}, \mathrm{C}_{70}, \mathrm{PC}_{60} \mathrm{BM}, \mathrm{PC}_{70} \mathrm{BM}$, BisPC ${ }_{60} \mathrm{BM}$, TrisPC ${ }_{60} \mathrm{BM}$ and $\mathrm{IC}_{60} \mathrm{BA}$ coated substrates via solution process, $\Phi_{\text {org/sub }}$, on the work function of bare substrate, $\Phi_{\text {sub. }}$ (b) Distribution of the pinning energies of the fullerenes with increasing the number of adducts. $E_{\mathrm{ICT}+}$ : positive pinning energy $(\mathrm{eV}) ; E_{\mathrm{ICT}-}$ : negative pinning energy $(\mathrm{eV}) ; D$ : the downshift energy of $\sim 0.2 \mathrm{eV}$ away from the "ideal" vacuum level alignment behavior. 

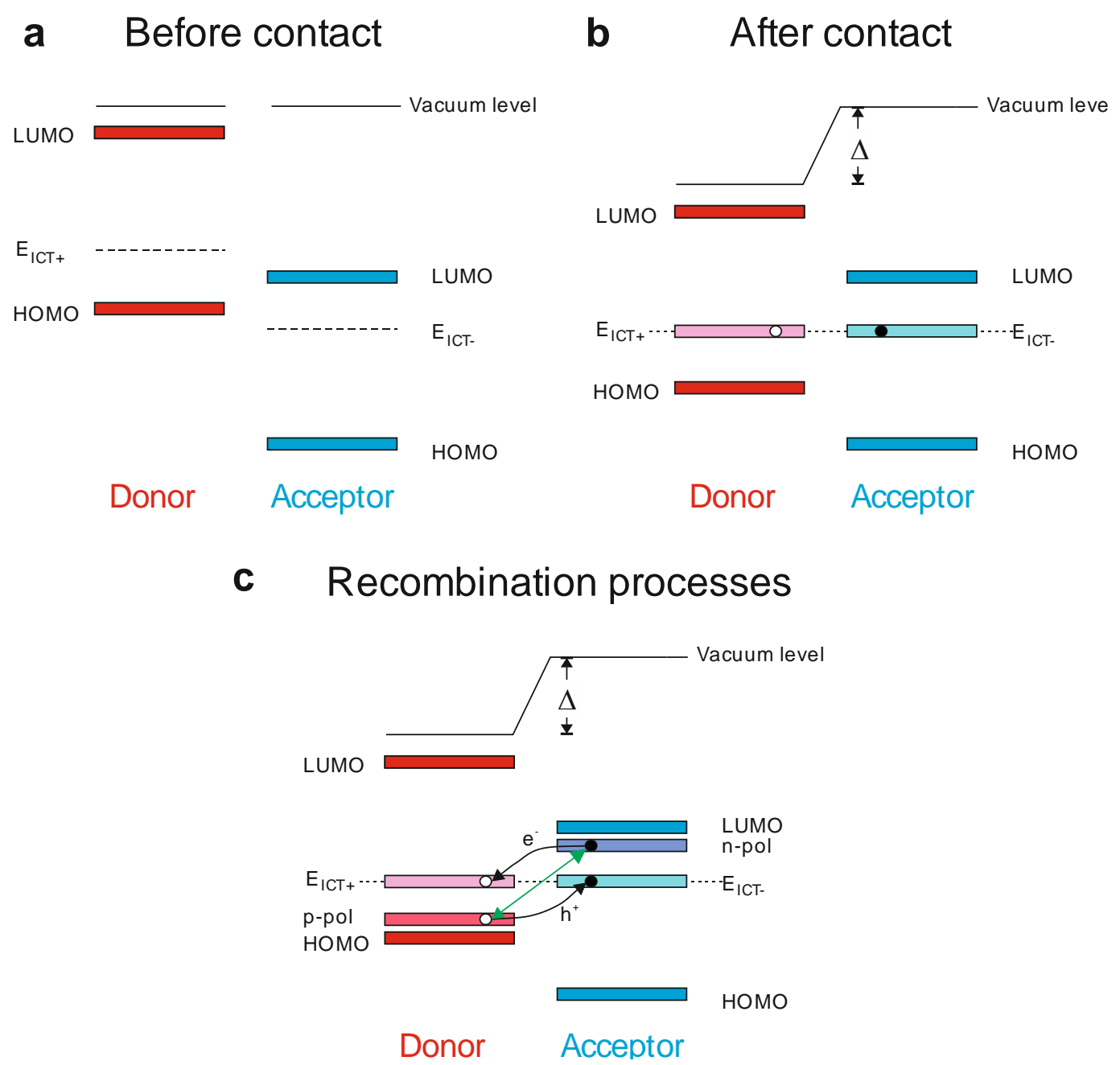

Figure 2. Energy level alignment diagrams for a donor-acceptor system before and after BHJ formation with a dipole shift introduced through ICT states. (a) Before contact. (b) The donor $\mathrm{E}_{\mathrm{ICT}+}$ is less the acceptor $\mathrm{E}_{\mathrm{ICT}}$, causing Fermi level equilibrium through spontaneous formation of ICT states at the interface and the formation of a potential energy step $(\Delta)$ upon contact. (c) During OPV operation, free negative polarons (n-pol) in the acceptor may recombine with the opposite-charged interface polarons $\left(\mathrm{E}_{\mathrm{ICT}+}\right)$ in the donor as the free n-polarons are situated above the donor $\mathrm{E}_{\mathrm{ICT}+}$. Correspondingly, free positive polarons (p-pol) in the donor may recombine with the opposite-charged interface polarons $\left(\mathrm{E}_{\mathrm{ICT}-}\right)$ in the acceptor as the free $\mathrm{p}$-polarons are situated below the acceptor $\mathrm{E}_{\mathrm{ICT} \text {-. Direct }}$ bimolecular recombination of free polarons is depicted with a green arrow. The highest occupied molecular orbital (HOMO) and lowest unoccupied molecular orbital (LUMO) of the donor (red) and acceptor (blue) are also depicted. 

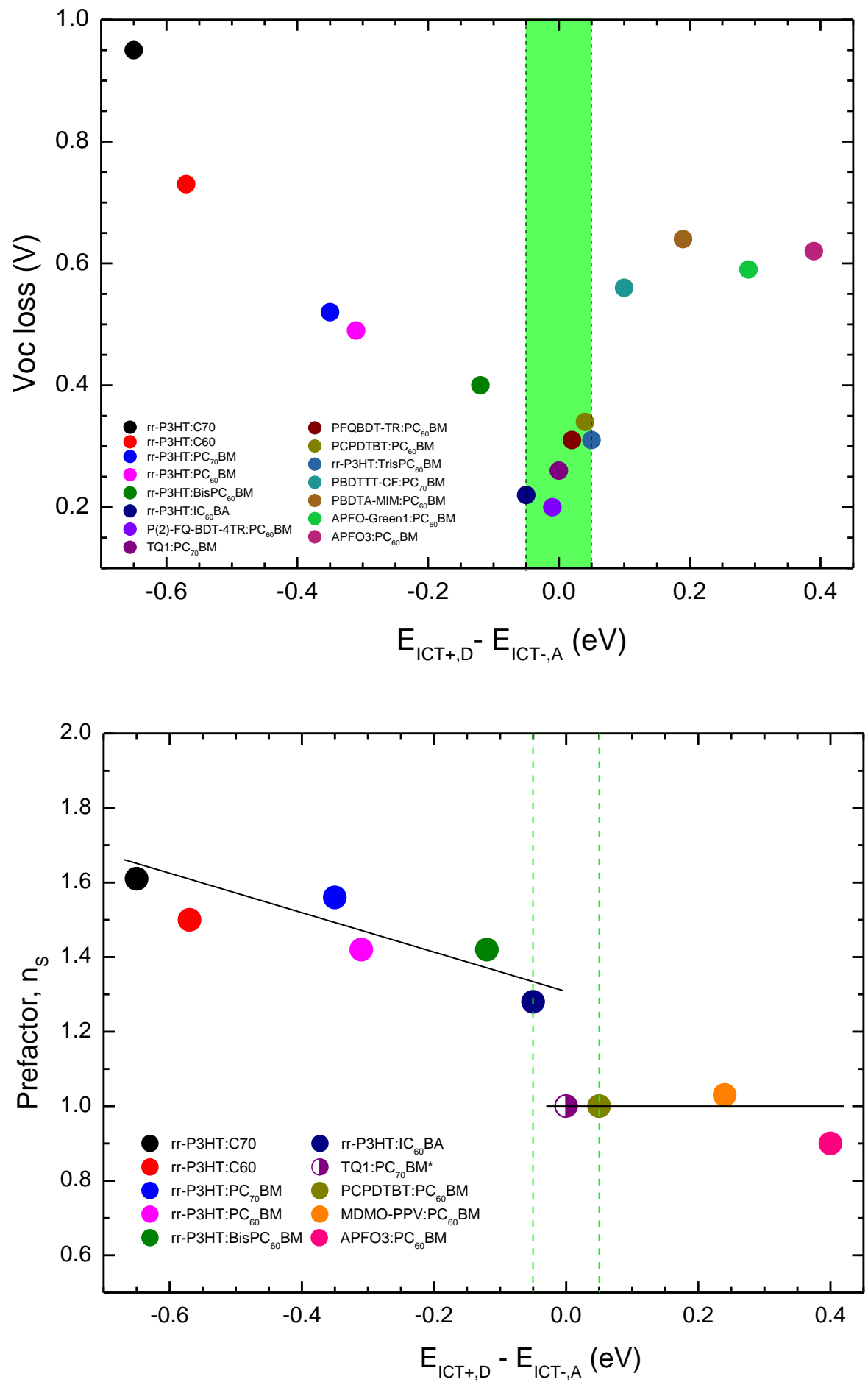

Figure 3. Top panel: $\mathrm{V}_{\mathrm{oc} \text { loss }}=\Delta E_{g, e f f}^{D A}-\mathrm{V}_{\mathrm{oc}}$, plotted against the $\mathrm{E}_{\mathrm{ICT}+\mathrm{D}}-\mathrm{E}_{\mathrm{ICT}-\mathrm{A}}$ for a set of polymer:fullerene blends. The plotted data are given in Table S1. The green region contains the polymer:fullerene blends where $\mathrm{E}_{\mathrm{ICT}+\mathrm{D}} \approx \mathrm{E}_{\mathrm{ICT}-\mathrm{A}}$ within the error bar of the measurement. Bottom panel: The corresponding light-ideality factor $n_{s}$ as a function of $\Delta$ for the rr- 
P3HT:fullerene series (see Table 1), PCPDTBT:PC $60 \mathrm{BM}^{[42]}$ and $\mathrm{APFO}_{3}: \mathrm{PC}_{60} \mathrm{BM}^{[43]} \mathrm{We}$ assign $n_{s} \approx 1$ for $\mathrm{TQ1}: \mathrm{PC}_{70} \mathrm{BM}$, as it exhibits pure bimolecular recombination. ${ }^{[4]}$ The $n_{s}$ factor and $\mathrm{E}_{\mathrm{ICT}+\mathrm{D}}$ for MDMO-PPV:PC ${ }_{60} \mathrm{BM}$ are derived from literature. ${ }^{[40,45]}$

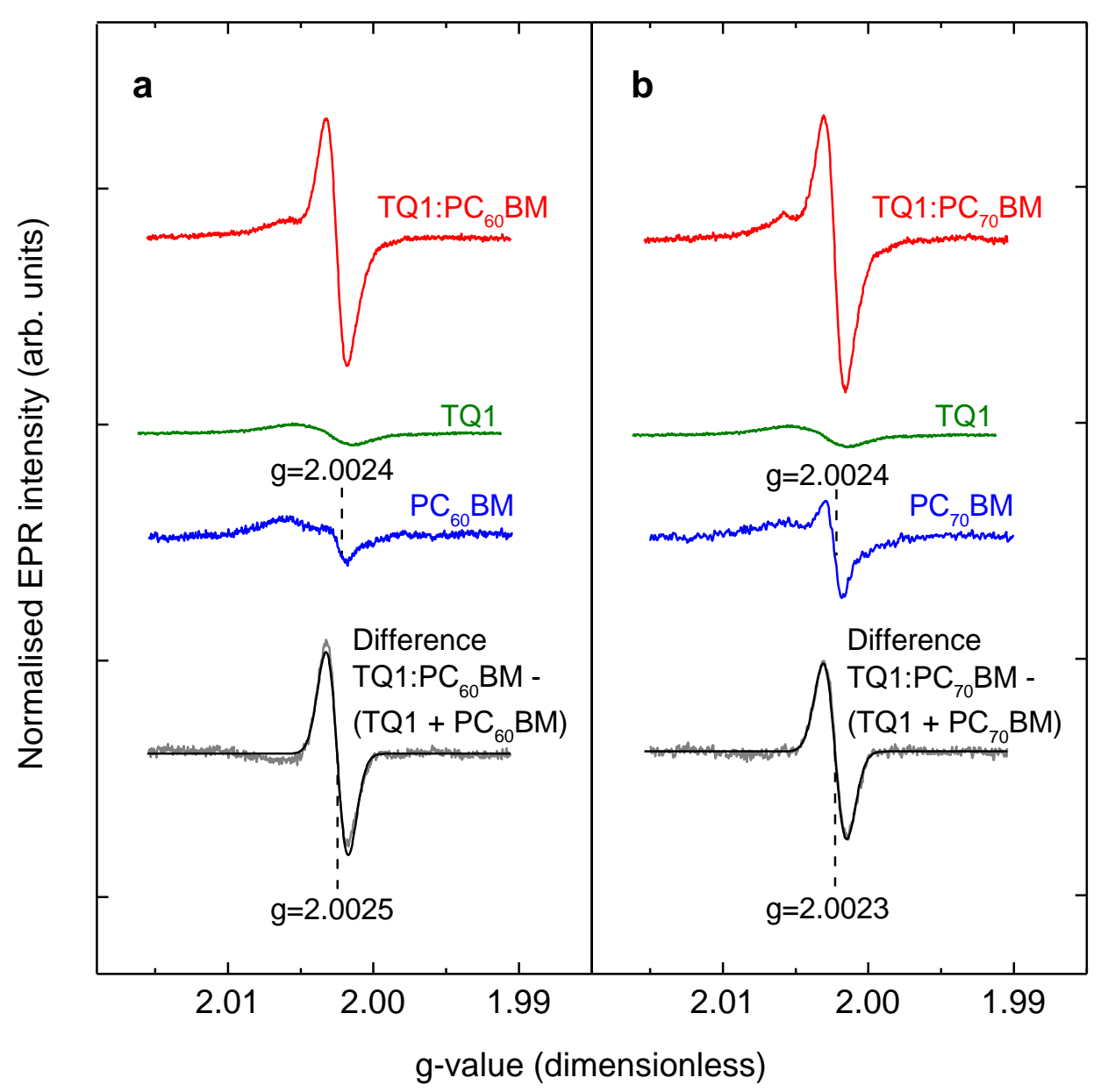

Figure 4. (a) EPR spectra, volume normalized, of a TQ1:PC ${ }_{60} \mathrm{BM} 1: 1$ blend film (red), neat $\mathrm{TQ} 1$ (green) and $\mathrm{PC}_{60} \mathrm{BM}$ films (blue). The difference between the EPR spectrum of the blend and a sum of the neat $\mathrm{TQ} 1$ (green) and $\mathrm{PC}_{60} \mathrm{BM}$ (blue) film spectra are shown by the lowest curve (grey), representing new spin-carrying species created at the bulk heterojunction with a g-factor of 2.0025 that is different from those from the neat films (see Fig.S8 for details). (b) The corresponding EPR spectra of a TQ1:PC ${ }_{70} \mathrm{BM} 1: 1$ blend film, neat $\mathrm{TQ} 1$ (green), $\mathrm{PC}_{70} \mathrm{BM}$ film (blue) and difference spectrum (grey). All EPR spectra are volume normalized and vertically shifted for clarity. 
Table 1. Summary of positive/negative pinning energy $\left(E_{\mathrm{ICT}+/-}\right)$, ionization potential (IP), electronic affinity (EA) of fullerenes, $\Delta$ : interface potential step obtained from difference between fullerene $E_{\mathrm{ICT}-}$ and rr-P3HT $E_{\mathrm{ICT}+}(\sim 4.0 \mathrm{eV}), \Delta E_{g}^{D A}=\mathrm{IP}_{\mathrm{D}^{-}} \mathrm{EA}_{\mathrm{A}}$ : the difference between the donor IP (rr-P3HT $\sim 4.6 \mathrm{eV}$ ) and (fullerene) acceptor EA, $\Delta E_{g, \text { eff }}^{D A}=\mathrm{IP}_{\mathrm{D}^{-}}$ $\mathrm{EA}_{\mathrm{A}}+\Delta$ : the difference between the donor IP and acceptor EA including the contribution from vacuum level misalignment at the BHJ, $V_{o c}$ of devices with a structure of ITO/PEDOT: PSS/rr-P3HT:fullerene/LiF/Al and $n_{s}$ : a prefactor related to the dominating recombination process in the rr-P3HT:fullerene blend (all $n_{s}$ values obtained from Tromholt, el al) ${ }^{[46]}$.

$\begin{array}{llllllllll}\text { Fullerene } & \boldsymbol{E}_{\mathrm{ICT}+} & \boldsymbol{E}_{\mathrm{ICT}-} & \text { IP } & \text { EA } & \Delta & \Delta E_{g}^{D A} & \Delta E_{g, e f f}^{D A} & \boldsymbol{V}_{\text {oc }} & \boldsymbol{n}_{s}\end{array}$

\begin{tabular}{|c|c|c|c|c|c|c|c|c|c|}
\hline $\mathrm{C}_{60}$ & 5.55 & 4.57 & 6.35 & $3.98^{[47]}$ & 0.57 & 0.62 & 1.19 & $0.46^{[46]}$ & 1.5 \\
\hline $\mathrm{C}_{70}$ & 5.48 & 4.65 & 6.30 & 3.98 & 0.65 & 0.62 & 1.27 & $0.32^{[46]}$ & 1.61 \\
\hline $\mathrm{PC}_{60} \mathrm{BM}$ & 5.32 & 4.31 & 6.10 & $3.80^{[47]}$ & 0.31 & 0.8 & 1.11 & $0.62^{[48]}$ & 1.42 \\
\hline $\mathrm{PC}_{70} \mathrm{BM}$ & 5.22 & 4.35 & 5.90 & 3.80 & 0.35 & 0.8 & 1.15 & $0.63^{[48]}$ & 1.56 \\
\hline $\mathrm{BisPC}_{60} \mathrm{BM}$ & 5.08 & 4.12 & 5.95 & $3.60^{[49]}$ & 0.12 & 1.0 & 1.12 & $0.72^{[46]}$ & 1.42 \\
\hline TrisPC $_{60} \mathrm{BM}$ & 4.95 & 3.95 & 5.85 & $3.50^{[50]}$ & 0 & 1.1 & 1.1 & $0.81^{[30]}$ & - \\
\hline $\mathrm{IC}_{60} \mathrm{BA}$ & 5.15 & 4.05 & 5.93 & $3.57^{[51]}$ & 0.05 & 1.03 & 1.08 & $0.86^{[31]}$ & 1.28 \\
\hline
\end{tabular}

The IPs were measured by ultraviolet photoelectron spectroscopy (UPS) and the cited EA values are from inverse photoemission spectroscopy (IPES) studies, see further discussion in the supporting information. EA values reported by IPES measurements scatter over a large range, e.g. for $\mathrm{PC}_{60} \mathrm{BM} \sim 0.35 \mathrm{eV}^{[47,52-54]}$, due to the inherent problems of the technique such as sample damage and comparatively low energy resolution. In the situations of ambiguity, we have used literature cyclic voltammetry measurements on the same systems to 
try to reconcile the different values into the ones given. For $\mathrm{C}_{70}$, we use the $\mathrm{EA}$ of $\mathrm{C}_{60}$ as cyclic voltammetry show that the reduction potential is $\sim$ identical ${ }^{[55]}$. $E_{\mathrm{ICT}+/-}, \mathrm{IP}, \mathrm{EA}, \Delta E_{g}^{D A}$ and $\Delta E_{g, \text { eff }}^{D A}$ are shown in units of $\mathrm{eV}$, and $V_{o c}$ is shown in units of $\mathrm{V}$.

The table of contents entry: The large variation in open circuit voltage for regioregularpoly(3-hexylthiophene):fullerene BHJ devices that yield a roughly constant effective donor ionization potential to acceptor electron affinity energy difference at the donor-acceptor interface is found to be a consequence of trap-assisted recombination via integer charge transfer states. Based on the results, novel design rules for organic BHJ photovoltaics are proposed.

Keywerds: pinning energy, trap-assisted recombination, interface, open circuit voltage, organic solar cell

Title: Trap-assisted recombination via integer charge transfer states in organic bulk heterojunction photovoltaics

By Qinye Bao, Oskar Sandberg, Daniel Dagnelund, Simon Sandén, Slawomir Braun, Harri Aarnio, Xianjie Liu, Weimin M. Chen, Ronald Österbacka and Mats Fahlman

Toc Figure:

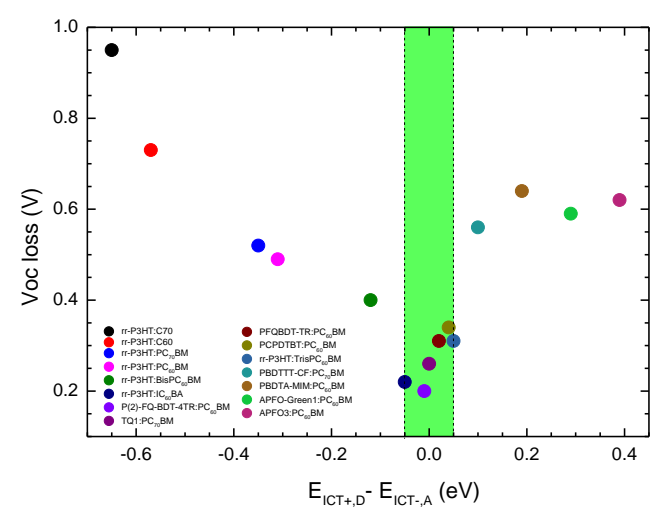




\section{Supplementary Information}

Trap-assisted recombination via integer charge transfer states in organic bulk heterojunction photovoltaics

Qinye Bao, ${ }^{1}$ * Oskar Sandberg, ${ }^{2}$ Daniel Dagnelund, ${ }^{3}$ Simon Sandén,,${ }^{2}$ Slawomir Braun, ${ }^{1}$

Harri Aarnio, ${ }^{2}$ Xianjie Liu, ${ }^{1}$ Weimin M. Chen, ${ }^{3}$ Ronald Österbacka ${ }^{2}$ and Mats Fahlman ${ }^{1}$ *

${ }^{1}$ Division of Surface Physics and Chemistry, Department of Physics, Chemistry and Biology, Linköping University, SE-58183 Linköping, Sweden.

${ }^{2}$ Center for Functional Materials, Department for Natural Sciences, Åbo Akademi University, FI-20500 Turku, Finland.

${ }^{3}$ Division of Functional Electronic Materials, Department of Physics, Chemistry and Biology, Linköping University, SE-58183 Linköping, Sweden

E-mail: qinba@ifm.liu.se, mats.fahlman@liu.se

Keywords: pinning energy, trap-assisted recombination, interface, open circuit voltage, organic solar cell

\section{Content includes:}

Supplementary background

Supplementary result

Supplementary discussion

Table S1

Figs. S1 to S8

References 


\section{Supplementary background}

When discussing energy level alignment at interfaces involving organic semiconductors $(\mathrm{OS})$, it is useful to define in more detail the physics involved, as concepts from inorganic crystalline semiconductors are often used in a confusing way. Most films involving OS are amorphous or at best polycrystalline. Indeed, in the particular case of bulk heterojunction solar cells, there is never single crystal films but the blends are rather amorphous or a mixture of well ordered (polycrystalline) regions and disordered (amorphous) regions. Hence, the concept of energy bands does not hold, and the electronic structure is defined by localized states (molecular orbitals). The ionization energy of these molecular orbitals strongly depends on the local environment, i.e. the intermolecular order and the nature of surrounding molecules/materials. Hence, though the ionization energies of the various occupied molecular orbitals are well defined for an isolated molecule, in a molecular film, there is a broad distribution of ionization energies for each orbital. ${ }^{[1,2]}$ Even though each molecule has e.g. a discrete energy corresponding to the removal of one electron from the highest occupied molecular orbital (HOMO), typically referred to as the Ionization Potential (IP) of the molecule, if then each molecule in the film has a unique local environment each IP will be unique and there will hence be a distribution of IP due to variations in the local molecular order. The same holds true for the unoccupied molecular orbitals, there is e.g. a distribution of Electron Affinities (EA) as well in the film. The energy gap is here then defined by the upper edge of the IP energy distribution and the lower edge of the EA energy distribution, and there are consequently per definition no gap states in absence of doping or molecular defects as the frontier IP/EA energies created by 
variations in molecular order define the actual gap. Note that this is fundamentally different from a single crystal where we have energy bands and a well-defined gap between the upper edge of the valence band and the lower edge of conduction band. Here, defects in the local order will create new localized states that sometimes appear in the energy gap (above the valence band edge or below the conduction band edge). The frontier part of the IP and EA distribution in OS films is typically modeled as being either Gaussian or exponential, and the most easily oxidized/reduced states in the IP/EA distributions are often then referred to as tail states. Sometimes such states are also referred to as gap states, though as mentioned above, this is unfortunate as there is then no proper definition of the actual energy gap for the disordered films and the positions in the IP and EA distribution that separates the gap states from the "proper" states becomes unclear and ill-defined.

When approaching the topic of energy level alignment featuring OS, it is also important to consider that oxidation/reduction of a OS molecule leads to reorganization of both the electronic and bond structure, i.e. the formation of polaronic states. As the energy needed to oxidize (gained from reducing) a molecule is decreased (increased) through this relaxation, the IP and EA is not identical to the HOMO and lowest unoccupied molecular orbital (LUMO) energies of the neutral molecule. As injecting and transporting charge through an OS film indeed involves either populating the HOMO with a hole or the LUMO with an electron, it is the IP and EA (positive and negative polaron energy) distributions in the film that are relevant.

The Integer Charge Transfer (ICT) model ${ }^{[3-5]}$ was developed to describe equilibrium energy level alignment at weakly-interacting interfaces involving organic semiconducting 
molecules such as organic-organic heterojunctions and inorganic-organic junctions prepared under ambient or high vacuum conditions i.e., the type of interfaces present in organic photovoltaics of the bulk heterojunction type. The model assumes that Fermi level equilibrium must be achieved across the whole multilayer stack in e.g. an OPV device, including interfaces. ${ }^{[3,6,7]}$ The ICT model predicts and explains the experimentally verified [8,9] abrupt transitions between a vacuum level alignment regime and Fermi-level pinning regimes upon variations of the work function of the substrate. The Fermi-level pinning regimes feature a potential step that scales with the difference between the equilibrium ionization potential or electron affinity of the organic semiconductor at the interface and the work function $\left(\Phi_{\text {sub }}\right)$ of the substrate. The origin of the potential step $(\Delta)$ is explained by spontaneous charge transfer across the interface via tunneling (integer charge transfer) when the substrate work function is higher than the energy required to take away one electron (lower than the energy gained from adding one electron) from (to) the molecule at an interface producing a fully relaxed state. The most easily oxidized donor molecules (or segments on polymers) hence will be "used up" until enough charge has been transferred across the interface to create a potential step that equilibrates the Fermi level. The energy where the Fermi level is subsequently pinned is referred to as $\mathrm{E}_{\mathrm{ICT}+,-}$ depending on if it is positive or negative polarons that are being created. Unless a crystal film, the interface polarons will be localized on one or more molecules (depending on local order, orbital overlap etc.), but will not be delocalized over the film in a band-like picture, as there are no bands. Note, the ICT states are not pre-existing polarons, nor are they photogenerated, they are created upon interface formation if equilibration of the Fermi level demands it. ${ }^{[4]}$ 
Furthermore, they do not have the same energy as bulk polarons, mainly due to Coulombic interaction with the opposite charge across the interface and variations in molecular order, ${ }^{[4]}$ more on that below. Three distinct energy level alignment regimes are predicted by the model at Fermi level equilibrium and are described by: (i) $\Phi_{\text {sub }}<\mathrm{E}_{\mathrm{ICT}-}-$ Fermi level pinning to a negative integer charge transfer state, resulting in a substrate-independent work function, slope $=0$; (ii) $\mathrm{E}_{\mathrm{ICT}-}<\Phi_{\text {sub }}<\mathrm{E}_{\mathrm{ICT}+}-$ Vacuum level alignment, giving a substratedependent work function, slope $=1$; (iii) $\Phi_{\text {sub }}>\mathrm{E}_{\mathrm{ICT}+}-$ Fermi level pinning to a positive integer charge transfer state, resulting again in a substrate-independent work function slope $=0$.

As mentioned above, the $\mathrm{E}_{\mathrm{ICT}+}\left(\mathrm{E}_{\mathrm{ICT}-}\right)$ energy is related to the energy required to take away one electron (the energy gained from adding one electron) from (to) the OS molecule at an interface producing a fully relaxed state. These energies are thus similar in nature to but differ from the ionization potential (IP) and electron affinity (EA) of the organic semiconductor, i.e. the polaronic transport states, such as $\mathrm{E}_{\mathrm{ICT}+}=\mathrm{IP}-\mathrm{B}^{+}$and $\mathrm{E}_{\mathrm{ICT}-}=\mathrm{EA}+$ $\mathrm{B}^{-}$, where $\mathrm{B}^{+}\left(\mathrm{B}^{-}\right)$is the Coulomb energy associated with charging a molecule in the interface layer with an hole (electron) ${ }^{[10,11]}$ see Fig. S1, and are thus moved into the gap compared to the bulk polarons. Note that IP, EA and $\mathrm{B}^{+}$and $\mathrm{B}^{-}$are all dependent on the local environment of the molecule, due to screening of the added charge, hence the $\mathrm{E}_{\mathrm{ICT}+,-}$ also depend on the local environment at the interface (inter- and intramolecular order, etc.). ${ }^{[4,11,12]}$ Despite the dependence on local order, fullerenes and conjugated polymers typically display $\mathrm{E}_{\mathrm{ICT}+,-}$ values independent on the substrate they are combined with. ${ }^{[3,8,9]}$ This may at first glance appear counterintuitive, but is a direct consequence of the non-single- 
crystalline nature of such films. Unless the surface energy of a particular substrate is radically different, the same types of local molecule order at the interface will be present upon film formation (to greater or lesser degree) and so are then the "most easily oxidized / reduced" sites that participate in the equilibration of the Fermi level. Hence, the EICT+,values obtained typically deviate very little $( \pm 0.05 \mathrm{eV})$ as can be seen from e.g. Fig. 1a even though both organic and inorganic substrates featuring different surface roughness, surface energy and potential for solvent-induced interface intermixing are used. However, for the cases where ordered films are formed and the orientation can be controlled by widely differing surface energy of the substrates, the expected order dependence in $\mathrm{E}_{\mathrm{ICT}+,-}$ values is indeed obtained. ${ }^{[12]}$ Also note that the ICT states formed at a D/A BHJ are Coulombically bound to each other, the positive polaron $\left(\mathrm{E}_{\mathrm{ICT}+}\right)$ in the donor interacting with the negative polaron ( $\mathrm{E}_{\mathrm{ICT}-}$ ) in the acceptor across the interface, as has been demonstrated e.g. for the $\mathrm{rr}-\mathrm{P} 3 \mathrm{HT} / \mathrm{C}_{60}$ system, where the singly occupied state from the $\mathrm{C}_{60}{ }^{-}$ molecules at the rr-P3HT interface is detected by Ultraviolet Photoelectron Spectroscopy (UPS). ${ }^{[13]}$

\section{Supplementary result}

\subsection{Ultraviolet photoelectron spectroscopy}

A series of fullerenes were studied in this work, see Fig. $\mathbf{S 2}$ for the chemical structure. The valence region occupied electronic structure and secondary electron cut-off was measured for each material by UPS using He I light $(\mathrm{h} v=21.2 \mathrm{eV})$, yielding the numerical values of IP (see Table 1) and work function. The IP values derived from UPS are taken 
from the leading edge of the frontier feature (and the density of states that extend away from this point are then often called tail states as mentioned earlier). This is a reproducible estimate and the one that you find cited in literature, but contains well-known inaccuracies as the bond relaxation part of the polaronic formation energy is not captured by the experiment and the the actual frontier edge of the IP distribution is lost in the noise level of the measurement. Typical valence region spectra for the fullerene series are depicted in Fig. S3 and the evolution dependent on fullerene cage and/or substituents can be followed. The main modifications of the frontier occupied electronic structure occur when changing the fullerene cage from $\mathrm{C}_{60}$ to $\mathrm{C}_{70}$, but we also see the expected general trend of energetic broadening upon adding substituents as we are introducing larger variations in inter- and intra-molecular order. UPS measurements were carried out to determine IP and $\mathrm{E}_{\mathrm{ICT}+}$ for the series of donor polymers used to test our design criteria and the results are given in Fig. S4 and Table S1.

\subsection{Near edge $x$-ray absorption fine structure}

To explore the shift in the vacuum level alignment region in Fig. 1a (main text) for trisPC ${ }_{60} \mathrm{BM}$, the Near Edge X-ray Adsorption Fine Structure (NEXAFS) spectrum of tris $\mathrm{PC}_{60} \mathrm{BM}$ was measured with the partial electron yield mode by applying negative bias to suppress electron with lower kinetic energy. Fig. S5 depicts the NEXAFS of trisPC ${ }_{60} \mathrm{BM}$ with $-180 \mathrm{~V}$ bias compared to the spectrum without bias. The intensities of the two spectra were normalized at the region of $\delta^{*}$ states around $293 \mathrm{eV}$. It can be clearly seen that the first LUMO related peak at $284.1 \mathrm{eV}$ is due to the contribution of $\mathrm{C}_{60}$ cage, the second peak 
at $284.6 \mathrm{eV}$ is from the adducts of tris $\mathrm{PC}_{60} \mathrm{BM}$, which was consistent with measurements on $\mathrm{PC}_{60} \mathrm{BM}{ }^{[14]}$ The spectral weight of the peak from the adducts is significantly enhanced at the $-180 \mathrm{~V}$ bias, whereas the signal from the $\mathrm{C}_{60}$ cage becomes relative weak. Due to the increased surface sensitivity of the partial electron yield mode, it hence can be concluded that the adducts of tris- $\mathrm{PC}_{60} \mathrm{BM}$ prefer to face towards the surface of the film. Such a preferential order supports (but not prove) the formation of a dipole that can shift the resulting work function as is displayed in Fig. 1.

\subsection{Photo-induced absorption}

Results from photo-induced absorption (PA) using above-gap excitation (514 nm) of rrP3HT mixed with either $\mathrm{PC}_{60} \mathrm{BM}$ or $\mathrm{IC}_{60} \mathrm{BA}$ is shown in Fig. S7a. In both blends we observe the spectrum typical of delocalized polarons in $\mathrm{rr}-\mathrm{P} 3 \mathrm{HT} .^{[15]}$ There is a slight difference between the two spectra. The low-energy (high-energy) band appears to be more red-shifted (blue-shifted) in rr-P3HT: $\mathrm{IC}_{60} \mathrm{BM}$, because the features corresponding to disordered polaron bands at $0.5 \mathrm{eV}$ and $1.6 \mathrm{eV}$ observed in $\mathrm{rr}-\mathrm{P} 3 \mathrm{HT}: \mathrm{PC}_{60} \mathrm{BM}$ blends are absent, ${ }^{[15]}$ suggesting that the rr-P3HT domains are less disordered in the $\mathrm{IC}_{60} \mathrm{BA}-$ based blends.

In Fig. S7b the PA spectrum of annealed rr-P3HT:IC ${ }_{60} \mathrm{BA}$ films using below gap (785 $\mathrm{nm} / 1.58 \mathrm{eV}$ ) is shown together with the PA spectrum of a similar film using rrP3HT:C 60 BM blend. From Fig. S7b

it is clear that the rr-P3HT: $\mathrm{IC}_{60} \mathrm{BA}$ film is not showing any photo-induced absorption bands using below-gap excitation in the measured wavelength range, in contrast to the rr- 
P3HT:PC ${ }_{60} \mathrm{BM}$ films. There may be a feature at $\sim 1.2 \mathrm{eV}$ which would correspond to polarons, but this feature, if present, is unresolvable from the background noice.

We also tested another system, TQ1:PC ${ }_{70} \mathrm{BM}$ blend films, that like rr-P3HT:IC $60 \mathrm{BA}$

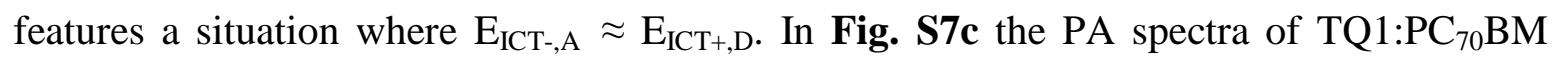
blend films using above-gap excitation $(514 \mathrm{~nm})$ and below gap $(785 \mathrm{~nm})$ are shown. A very slight signal, barely above the noice level, corresponding to polarons is seen for this case.

\subsection{Electron paramagnetic resonance}

To exclude the presence of photogenerated CT states and detect ICT states even at low densities, the highly sensitive technique of electron paramagnetic resonance (EPR) carried out in the dark was used. Initially, rr-P3HT:PC ${ }_{60} \mathrm{BM}$ and $\mathrm{rr}-\mathrm{P} 3 \mathrm{HT}: \mathrm{IC}_{60} \mathrm{BA}$ blends were studied but as EPR spectra showed that rr-P3HT neat films contain a significant density of spin-carrying species, we instead chose the TQ1 polymer as its spin carrying density in neat

films were in order $10^{3}$ lower than rr-P3HT and hence allowed detailed study of the $\mathrm{E}_{\mathrm{ICT}-\mathrm{A}}$ $\approx \mathrm{E}_{\mathrm{ICT}+, \mathrm{D}}$ case where little (if any) ICT density is expected to be generated.

EPR spectra taken in the dark of neat TQ1 films, $\mathrm{PC}_{60} \mathrm{BM}$ films and $\mathrm{PC}_{70} \mathrm{BM}$ film as well as $\mathrm{TQ1}: \mathrm{PC}_{60} \mathrm{BM}$ and $\mathrm{TQ1}: \mathrm{PC}_{70} \mathrm{BM}$ 1:1 blend films are shown in Fig. S8. The experimental (black) curves for the neat films are deconvoluted into separate contributing EPR signals that are shown below the top (experiemental) curve and the simulated EPR spectra (red), with the respective g-factors listed. For the TQ1:PC ${ }_{60} \mathrm{BM}$ and TQ1:PC ${ }_{70} \mathrm{BM}$ 1:1 blend films the spectra are fitted with a 1:1 combination of the respective neat film pair 
+ an extra signal representing new spin-carrying species created at the bulk heterojunction. The new signal dominates the blends EPR spectra, highlighting that the blend signal is from newly created species (polarons) that are different from the defect/impurity states that induce EPR signals in the neat films.

\subsection{Derivation of $V_{o c}$ when trap-assisted recombination via ICT states dominates}

At open-circuit conditions the photo-generation rate of free charge carriers is cancelled by recombination and we have: $G \approx R=R_{\text {direct }}+R_{\text {trap-assisted }}$. The recombination rate for electrons and holes, can be expressed as: ${ }^{[16]}$

$R_{n} \approx \beta n p+\beta_{n} n p_{t}$

$R_{p} \approx \beta n p+\beta_{p} n_{t} p$

respectively. The density of electrons in the fullerene $E_{I C T}$ - states trapped at the BHJ interface is equal to the density of holes in the polymer $E_{I C T+}$ states trapped at the BHJ interface, $n_{t}=p_{t}=N_{I C T}$. If trap-assisted recombination via ICT states becomes comparable with direct bimolecular recombination, assuming $\beta_{n} \approx \beta_{p}=\beta_{S R H}$ and that $N_{I C T}$ is large and approximately constant (for $\mathrm{E}_{\text {ICT }+ \text {,- }}$ situated deep in the gap), we have

$G=\beta n p+\beta_{S R H} n p_{t} \approx \beta n p+\beta_{S R H} n N_{I C T}$

Setting the amount of photo-generated carriers to be approximately equal $\approx p$, using the expression $=N_{c} N_{v} \exp \left(\frac{e V_{o c}-\Delta E_{g, e f f}^{D A}}{k T}\right)$, see Ref. [S4], and solving for the open-circuit voltage $V_{o c}$, we then obtain: 
$e V_{o c}=\Delta E_{g, e f f}^{D A}-k T \ln \left(\frac{\beta N_{c} N_{v}+\beta_{S R H} N_{I C T} \sqrt{N_{c} N_{v}} \exp \left(\frac{\Delta E_{g, e f f}^{D A}-e V_{o c}}{2 k T}\right)}{G}\right)$

If trap-assisted recombination via ICT states is much larger than direct bimolecular recombination Eq. S4 reduces to:

$e V_{o c}=\Delta E_{g, e f f}^{D A}-2 k T \ln \left(\frac{\beta_{S R H} N_{I C T} \sqrt{N_{C} N_{v}}}{G}\right)$

Similar arguments have been used to derive the expression for $V_{o c}$ assuming various dominating recombination mechanisms in the past. ${ }^{[17,18]}$ For example if direct bimolecular recombination is the dominating recombination process one obtains:

$e V_{o c}=\Delta E_{g, e f f}^{D A}-k T \ln \left(\frac{\beta N_{c} N_{v}}{G}\right)$

Note that since $G=G_{L}+G_{t h}$, where $G_{L}$ is the generation rate $\left(G_{L}>>G_{t h}\right)$ and the thermal generation rate is in this case $G_{t h}=\beta N_{c} N_{v} \exp \left(-\frac{\Delta E_{g, e f f}^{D A}}{k T}\right)$, we may rewrite Eq. S6 as:

$e V_{o c}=k T \ln \left(\frac{G_{L}}{G_{t h}}+1\right)=k T \ln \left(\frac{J_{s c}}{J_{0}}+1\right)$

under the assumption that $J_{s c} \propto G_{L}$ (that is: the short-circuit current equals the saturated photo-current in reverse bias).

\section{Supplementary discussion}

For the case of pinned electrode contacts, the $V_{o c}$ is suggested to be controlled by the donor/acceptor blend as mentioned in the main text and can be described by metalinsulator-metal based models such as done by Tress et al. Potscavage, et al., ${ }^{[19]}$ used an alternative pn-junction based approach to obtain the following formula: 


$$
e V_{o c}=\frac{n}{n^{\prime}} \Delta E_{H L}-n k T \ln \left\{\frac{J_{00}}{J_{S C}}\right\}
$$

where $n$ is the ideality factor, $\Delta E_{H L}$ is the difference between the IP of the donor and the EA of the acceptor before junction formation, $n^{\prime}$ is a factor that accounts for effects such as vacuum level misalignments at the BHJ that modify the activation energy gained from $\Delta E_{H L}$ and $J_{0 O}$ is related to the reverse saturation current density. (Note by replacing $\Delta E_{H L} / n^{\prime}$ with $\Delta E_{g, e f f}^{D A}, \Delta E_{H L}$ with $\Delta E_{g}^{D A}, J_{S C} / J_{00}$ with $G / \beta N_{C} N_{V}$ we have re-obtained Eq. 1 in the main text assuming $n=1$ ). Again noting from Table 1 in the main text, the variation in effective $\Delta E_{H L}$ for the rr-P3HT:fullerene series is comparatively small and cannot explain the corresponding variation in $V_{O C}$, so we look to the $J_{O O} / J_{S C}$ ratio, see Eq. $S 8$. One demonstrated way of improving the photogeneration of free charges is through an ICT states induced dipole at the BHJ with the negative charge on the acceptor side. ${ }^{[20]}$ However, the presence of these ICT states may increase $J_{00}$, as $J_{00}$ strongly depends on both the surface density of interacting donor-acceptor pairs and their electronic coupling matrix element, ${ }^{[19]}$ which will act towards decreasing $V_{o c}$. Hence there is a trade-off: forming a ICT state by choosing a donor:acceptor combination so that the donor $\mathrm{E}_{\mathrm{ICT}+} \leq$ acceptor $\mathrm{E}_{\mathrm{ICT}-}$ contributes to enhanced probability of generating free charges (polarons) through dissociation of photogenerated CT complexes, ${ }^{[20]}$ while on the other hand, the presence of ICT states at the BHJ may increase $J_{00}$ and hence contribute to loss in $V_{o c}$, which in turn decreases PCE. The data summarized in Table 1 of main text suggest that the "sweet spot"

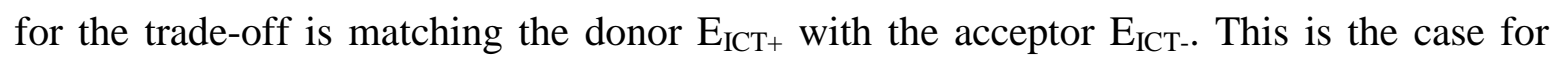
$\mathrm{IC}_{60} \mathrm{BA}$ and trisPC ${ }_{60} \mathrm{BM}$, both having $\mathrm{E}_{\mathrm{ICT}}$ - equal to the rr-P3HT $\mathrm{E}_{\mathrm{ICT}+}$ within the measurement error of the technique. $\mathrm{IC}_{60} \mathrm{BA}$ and trisPC${ }_{60} \mathrm{BM}$ have the two highest $V_{o c}$ 
values of the series (even though featuring the two lowest $\Delta E_{H L} / n^{\prime}$ after $\mathrm{C}_{70}$ ). The $\mathrm{IC}_{60} \mathrm{BA}$ based devices in fact have a slightly higher $V_{o c}$ than the tris $\mathrm{PC}_{60} \mathrm{BM}$ devices, which in part may be correlated to the comparatively low $J_{s c}$ of the latter.

To test if matching an acceptor $\mathrm{E}_{\mathrm{ICT}-}$ so as to be equal (or smaller) than the donor $\mathrm{E}_{\mathrm{ICT}+}$ reduce the D/A electronic coupling at an interface and hence reduce the loss in $V_{o c}$, we use photo-induced absorption (PA) measurements on annealed rr-P3HT:PC ${ }_{60} \mathrm{BM}$ (donor $\mathrm{E}_{\mathrm{ICT}+}$ $<$ acceptor $\mathrm{E}_{\mathrm{ICT}-}$ ) and annealed rr-P3HT:IC ${ }_{60} \mathrm{BM}$ (donor $\mathrm{E}_{\mathrm{ICT}+} \approx$ acceptor $\mathrm{E}_{\mathrm{ICT}-}$ ), see supplementary information section 2.3. In annealed rr-P3HT:PC ${ }_{60} \mathrm{BM}$ blends we previously have demonstrated direct photogeneration of charge transfer states using below-gap excitation, ${ }^{[20]}$ in agreement with the strong donor-acceptor coupling predicted by the respective $\mathrm{E}_{\mathrm{ICT}+,-}$ values. For annealed rr-P3HT: $\mathrm{IC}_{60} \mathrm{BM}$ blends, however, no feature belonging to direct photogeneration of charge transfer complexes (or free polarons) are observed when using below-gap excitation, demonstrating a much weaker donor-acceptor coupling at the bulk heterojunction (also the case for TQ1:PC ${ }_{70} \mathrm{BM}$ blends as shown in section 2.3). Hence, by matching the acceptor $\mathrm{E}_{\mathrm{ICT}}$ to be equal (or smaller) than the donor $\mathrm{E}_{\mathrm{ICT}+}$, we can significantly reduce the donor-acceptor coupling while maintaining the $\sim$ same effective donor IP - acceptor EA (and donor EA - acceptor EA) energy difference at the heterojunction as compared to the other (stronger) acceptors, thereby obtaining the highest $V_{o c}$. We thus can propose the same basic design rules as before: (i) electrodes should be chosen so that contacts are pinned: $\Phi_{\text {anode }} \geq \mathrm{E}_{\mathrm{ICT}+\mathrm{D}}$ and $\Phi_{\text {cathode }} \leq \mathrm{E}_{\mathrm{ICT}-\mathrm{A}}$ and (ii) donor:acceptor combinations should be chosen so that $\mathrm{E}_{\mathrm{ICT}-\mathrm{A}} \approx \mathrm{E}_{\mathrm{ICT}+\mathrm{D}}$ independent on 
using a pn-junction or a metal-insulator-metal approach to model the bulk heterojunction cells. 
Table S1. Summary of donor polymer positive pinning energy $\left(E_{\mathrm{ICT}+}\right)$, ionization potential (IP) measured by UPS, the effective donor IP and acceptor EA gap including the contribution from vacuum level misalignment at the $\mathrm{BHJ}\left(\Delta E_{g, e f f}^{D A}\right)$, open circuit voltage $\left(V_{o c}\right)$ of devices with pinned contacts and the open circuit voltage loss $\left(\mathrm{V}_{\text {oc loss }}=\Delta E_{g, \text { eff }}^{D A}-V_{o c}\right)$. $\mathrm{PC}_{60} \mathrm{BM}$ is used as the acceptor in all cases except $*$ where $\mathrm{IC}_{60} \mathrm{BA}$ and $* * \mathrm{PC}_{70} \mathrm{BM}$ was used.

\begin{tabular}{|c|c|c|c|c|c|}
\hline Polymer & $E_{\mathrm{ICT}+}$ & IP & $\Delta E_{g, e f f}^{D A}$ & $V_{o c}$ & $\mathbf{V}_{\text {oc loss }}$ \\
\hline rr-P3HT* & 4.0 & 4.6 & 1.08 & 0.86 & 0.22 \\
\hline rr-P3HT & 4.0 & 4.6 & 1.11 & 0.62 & 0.49 \\
\hline P2-FQ-BDT4TR & 4.3 & 4.9 & 1.1 & $0.9^{[21]}$ & 0.2 \\
\hline PCPDTBT & 4.37 & 4.8 & 1.0 & $0.65^{[22]}$ & 0.35 \\
\hline $\mathrm{TQ} 1 * *$ & 4.35 & 4.95 & 1.15 & $0.89^{[23]}$ & 0.26 \\
\hline PFQBDT-TR1 & 4.33 & 4.95 & 1.15 & $0.84^{[24]}$ & 0.31 \\
\hline APFO-green1 & $4.6^{[25]}$ & $5.1^{[25]}$ & 1.3 & $0.69^{[26]}$ & 0.59 \\
\hline PBDTTT-CF** & 4.45 & 5.12 & 1.32 & $0.76^{[27]}$ & 0.56 \\
\hline
\end{tabular}




\begin{tabular}{lccccc} 
PBDTA-MIM & 4.5 & 5.24 & 1.44 & $0.8^{[28]}$ & 0.64 \\
APFO3 & 4.7 & 5.4 & 1.6 & $0.98^{[29]}$ & 0.62 \\
\hline
\end{tabular}




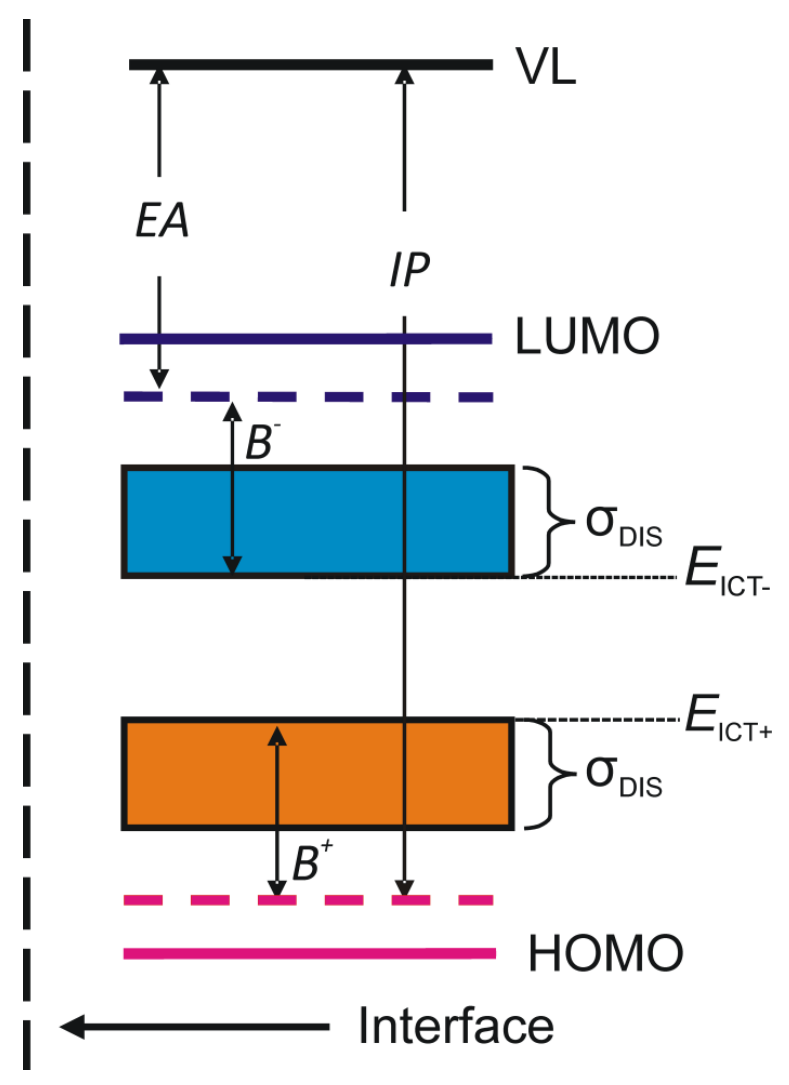

Figure S1. Energy level diagram of organic molecules at an interface: electron affinity distribution edge (EA), ionization potential distribution edge (IP), ICT energies ( $\left.\mathrm{E}_{\mathrm{ICT}+,-}\right)$ and highest occupied molecular orbital (HOMO) distribution edge and lowest unoccupied molecular orbital distribution (LUMO) edge are depicted in relation to the vacuum level (VL). $\sigma_{D I S}$ represents the pining energy distribution depending on intermolecular order, coulomb interaction, etc., i.e., the distribution of interface polaron energies of the sites available at a heterojunction. 


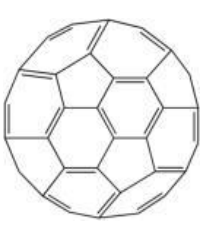

C60

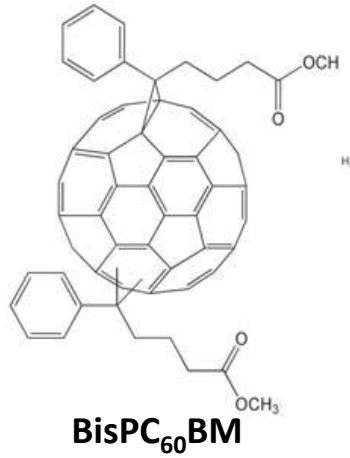

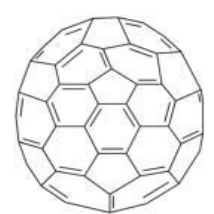

C70

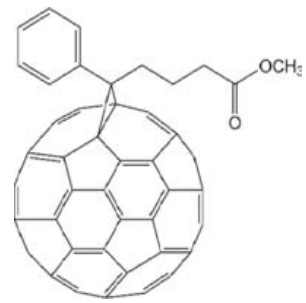

$\mathrm{PC}_{60} \mathrm{BM}$

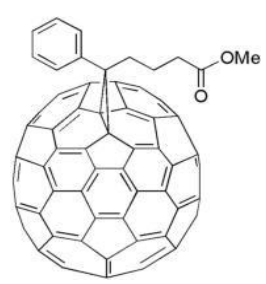

$\mathrm{PC}_{70} \mathrm{BM}$

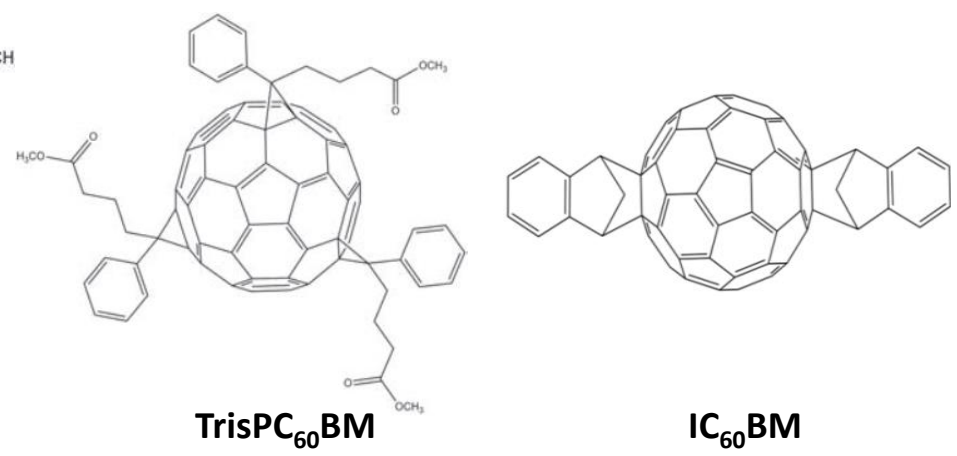

Figure S2. Chemical structures of fullerene and its derivatives considered in this study. 


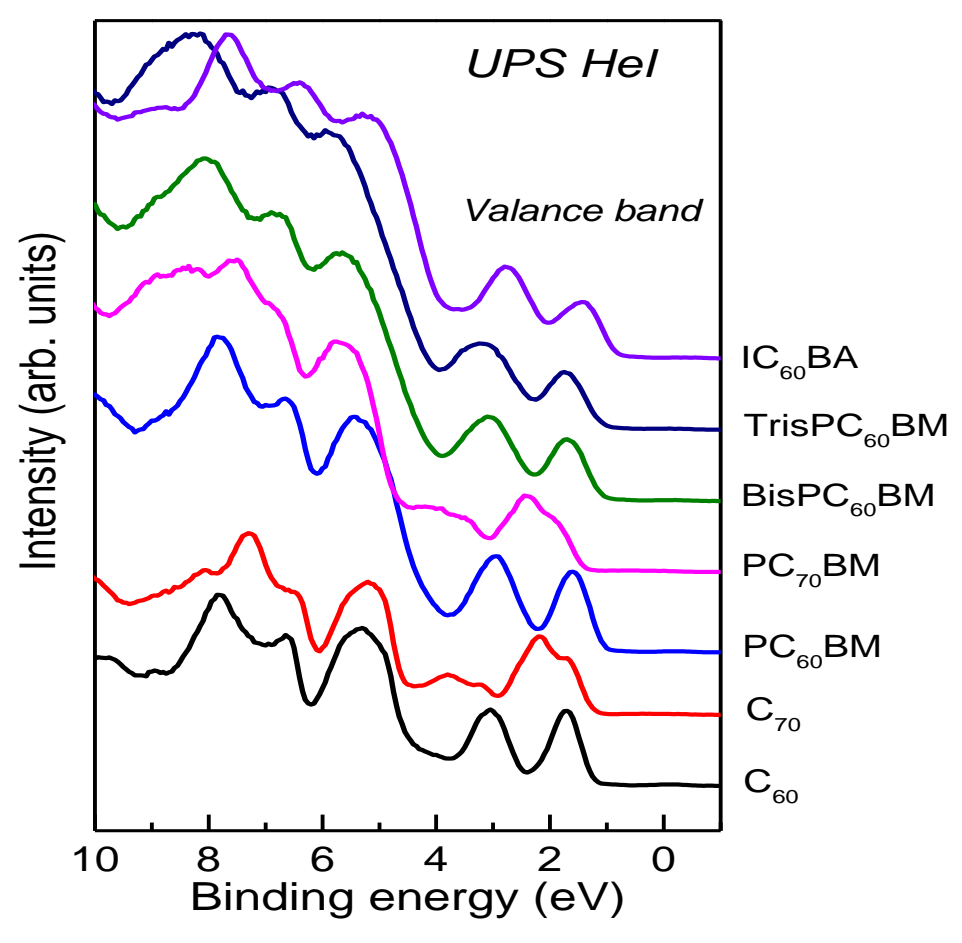

Figure S3. UPS spectra of the frontier occupied electronic structure of the fullerene series studied. 


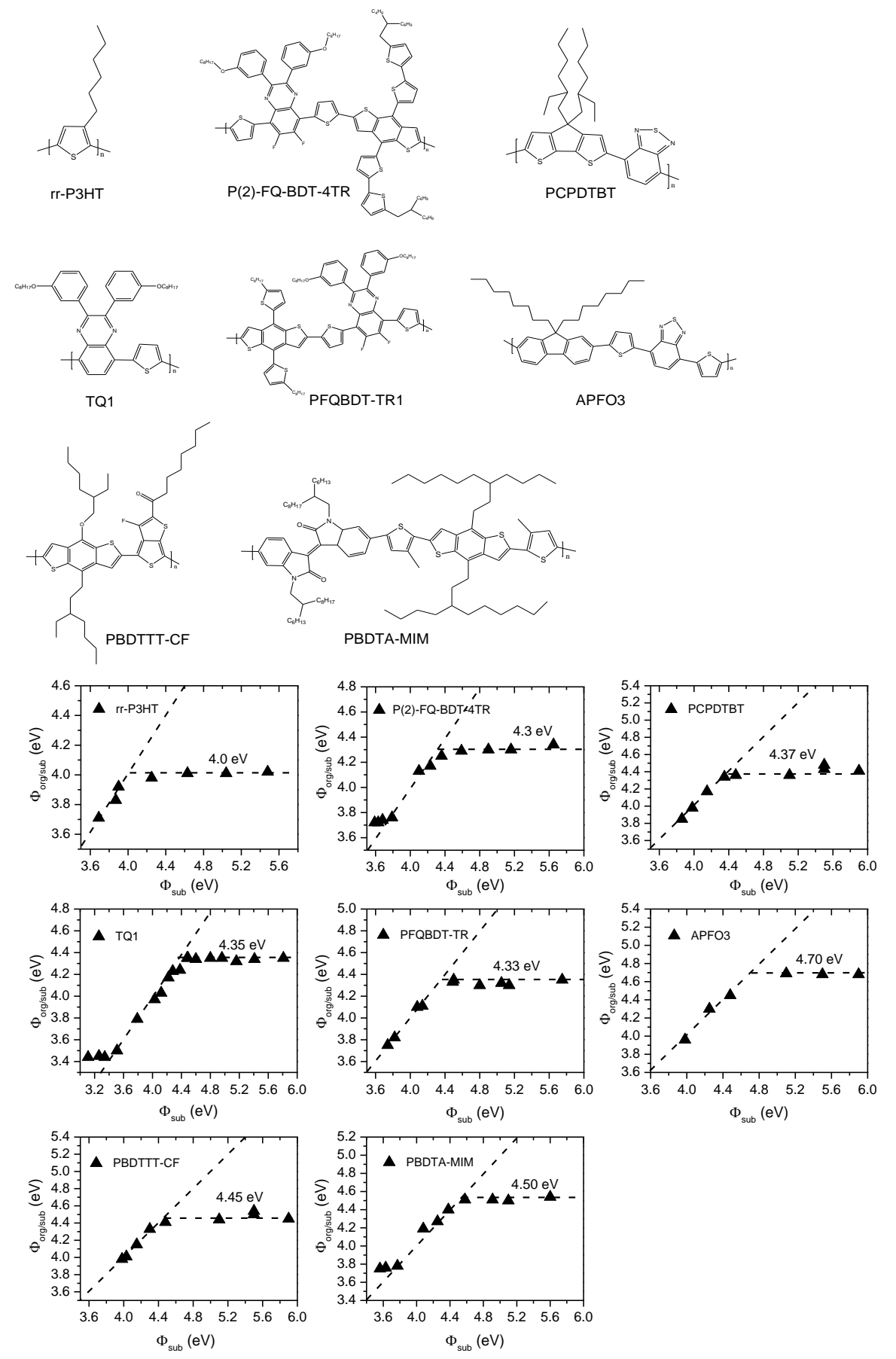

Figure S4. Chemical structure and pinning energies of a series of donor polymers. Dependences of the work function of donor polymer coated substrates via solution process, $\Phi_{\text {org/sub }}$, on the work function of bare substrate, $\Phi_{\text {sub }}$. 


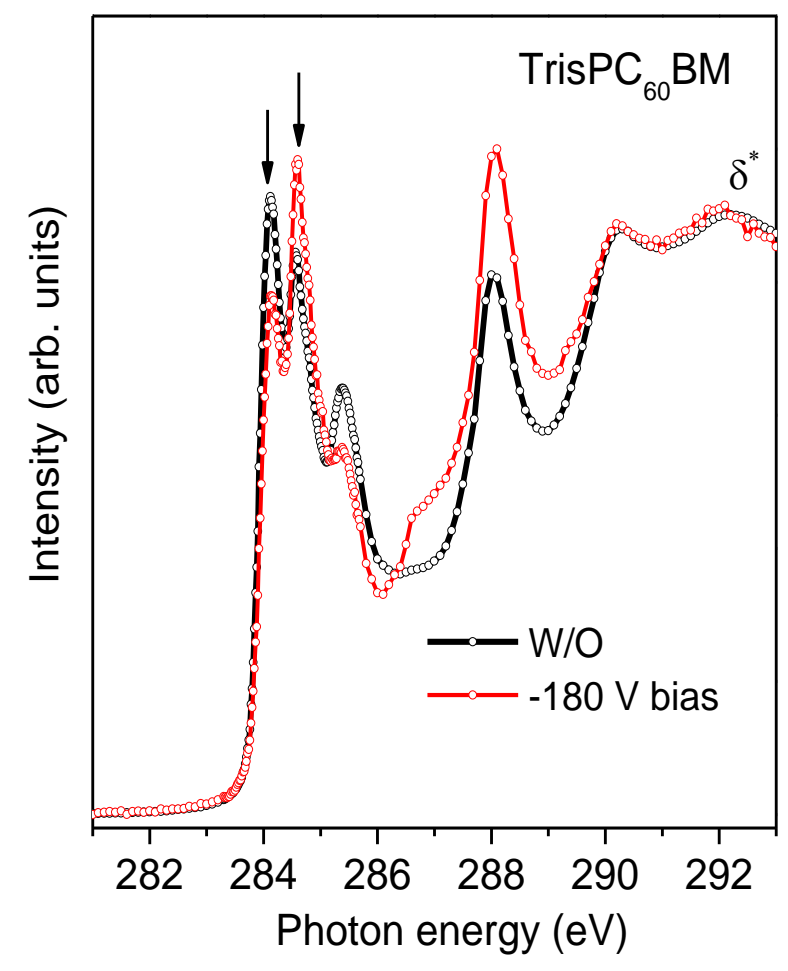

Figure S5. NEXAFS spectra of trisPC ${ }_{60} \mathrm{BM}$ with $-180 \mathrm{~V}$ bias and without bias. 
a

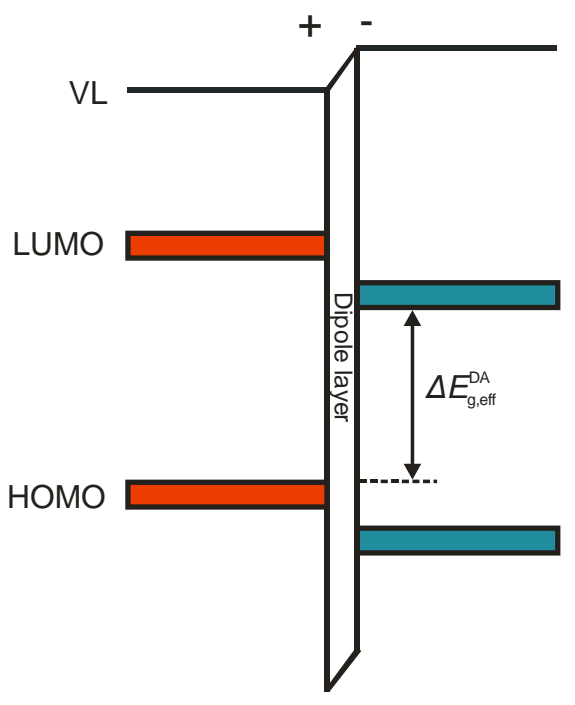

Donor Acceptor b

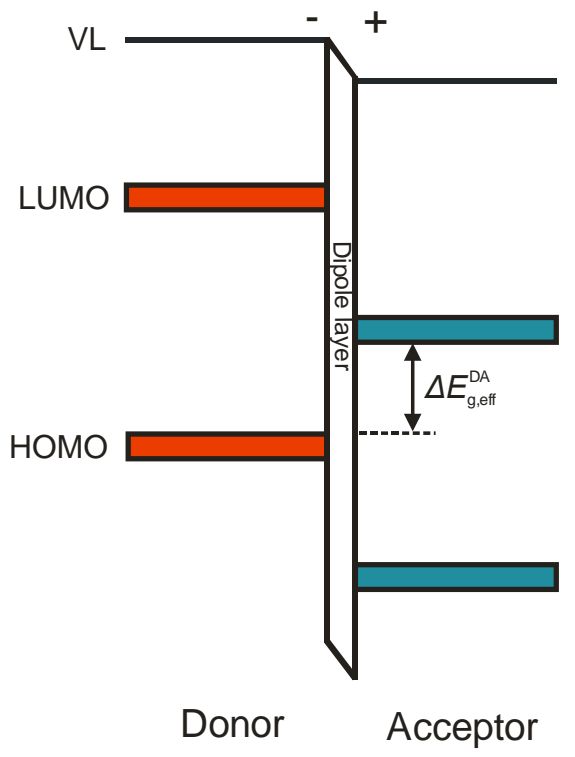

Figure S6. Energy level alignment diagrams of an inserted dipole layer between donor and acceptor. (a) A dipole layer with the negative side at the acceptor. (b) A dipole layer with the negative side at the donor. $\Delta E_{g, e f f}^{D A}$ represents the energy difference between donor IP and acceptor EA including the contribution from an inserted interfacial dipole layer. 

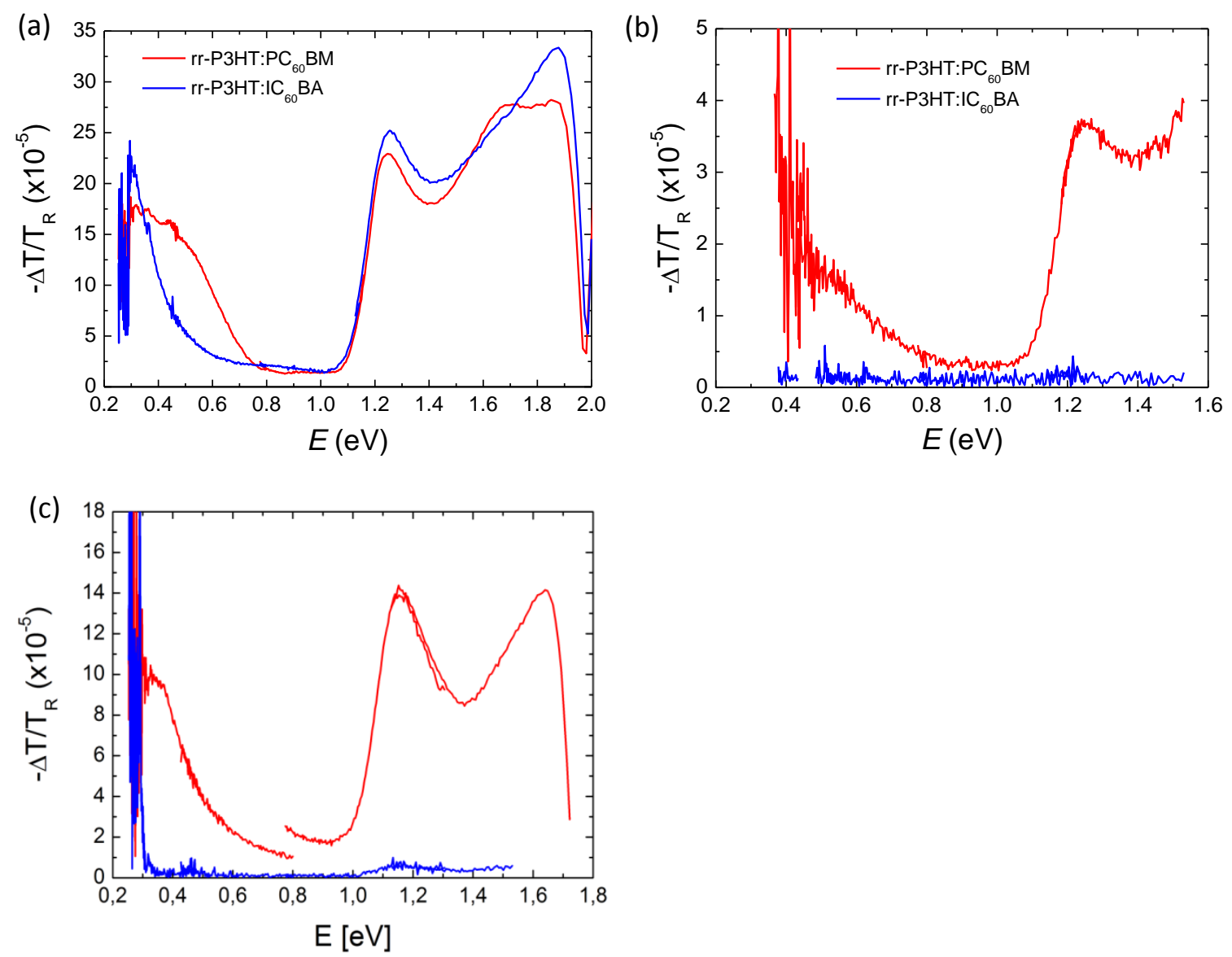

Figure S7. Photo-induced absorption spectra showing the radius signal for annealed films of rr-P3HT:PC ${ }_{60} \mathrm{BM}$ (red) and rr-P3HT:IC ${ }_{60} \mathrm{BA}$ (blue) pumped at (a) $514 \mathrm{~nm} / 2.41 \mathrm{eV}$ (above-gap), and (b) at $785 \mathrm{~nm} / 1.58 \mathrm{eV}$ (below-gap). (c) Photo-induced absorption spectra showing the radius signal for annealed films of $\mathrm{TQ1}: \mathrm{PC}_{70} \mathrm{BM}$ pumped at 514 $\mathrm{nm} / 2.41 \mathrm{eV}$ (red, above-gap) and at $785 \mathrm{~nm} / 1.58 \mathrm{eV}$ (blue, below-gap). 

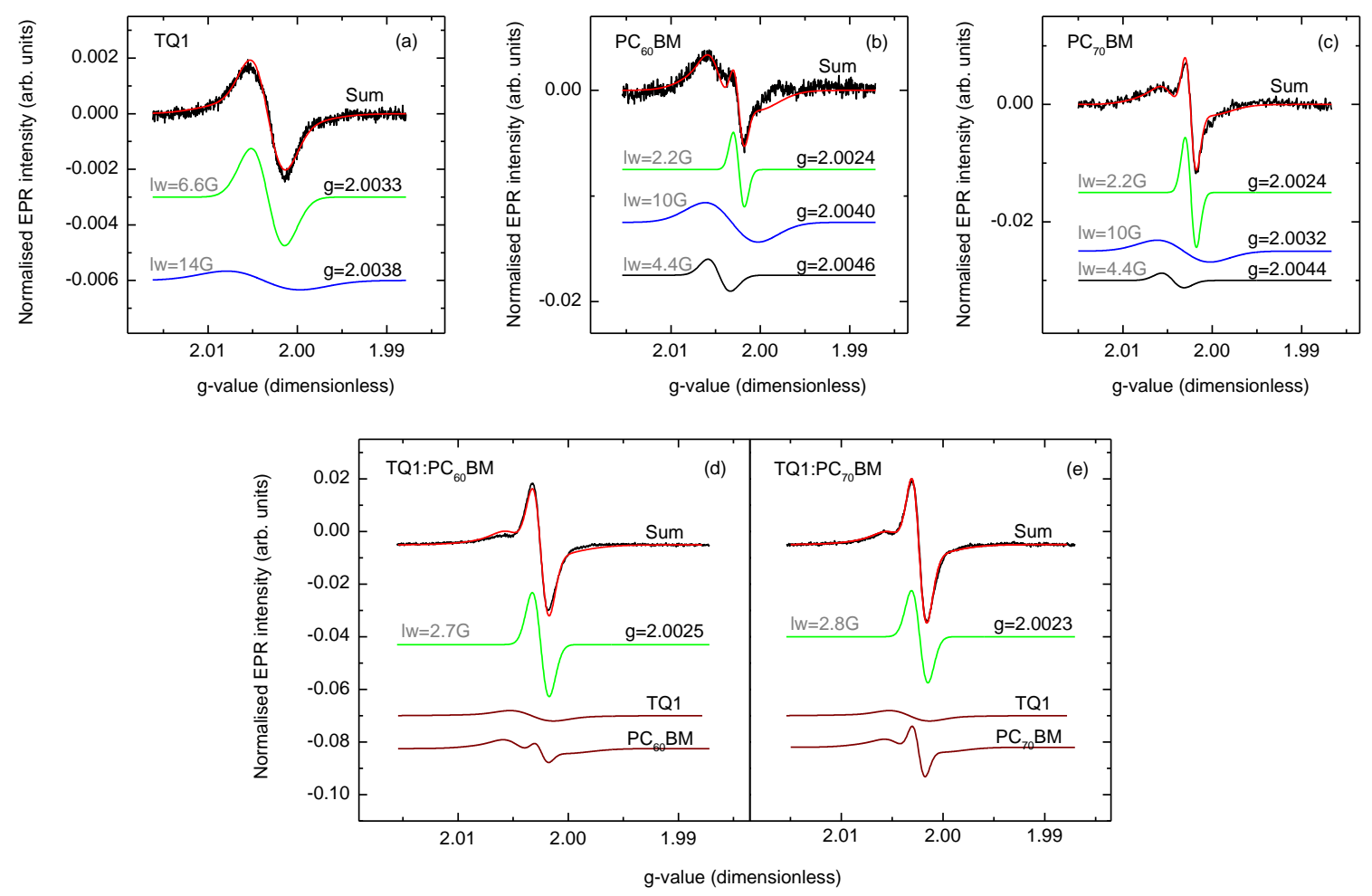

Figure S8. EPR spectra of (a) a neat TQ1 film, (b) a neat $\mathrm{PC}_{60} \mathrm{BM}$ film, (c) a neat $\mathrm{PC}_{70} \mathrm{BM}$ film, (d) a TQ1:PC ${ }_{60} \mathrm{BM}$ 1:1 blend film, and (e) a TQ1:PC ${ }_{70} \mathrm{BM}$ 1:1 blend film. The top curves in (a)-(e) represent the experimental (black) and simulated EPR spectra (red). The latter are sums of the contributing EPR signals, shown below the top curves, with the given g-factors. In (d) and (e), the spectra are volume normalized. The EPR signals of the blend films represent new spin-carrying species created at the bulk heterojunction. Note also the similarity between the blend spectra shown in (d) and (e) and the dissimilarity between the $\mathrm{PC}_{60} \mathrm{BM}$ (b) and $\mathrm{PC}_{70} \mathrm{BM}$ (c) spectra, also highlighting that the blend signal is from newly created species (polarons) that are different from the defect/impurity states that induce EPR signals in the neat films. All EPR spectra are volume normalized and vertically shifted for clarity 


\section{References}

1. S. Duhm, G. Heimel, I. Salzmann, H. Glowatzki, R. L. Johnson, A. Vollmer, J. P. Rabe, and N. Koch, Nature Mater. 2008, 7, 326.

2. W. R. Salaneck, Phys. Rev. Lett. 1978, 40, 60.

3. S. Braun, W. R. Salaneck, and M. Fahlman, Adv. Mater. 2009, 21, 1450.

4. M. Fahlman, A. Crispin, X. Crispin, S. K. M. Henze, M. P. de Jong, W. Osikowicz, C. Tengstedt, and W. R. Salaneck, J. Phys. Condens. Matter Inst. Phys. J 2007, 19, 183202.

5. C. Tengstedt, W. Osikowicz, W. R. Salaneck, I. D. Parker, C.-H. Hsu, and M. Fahlman, Appl. Phys. Lett. 2006, 88, 053502.

6. S. Braun, X. Liu, W. R. Salaneck, and M. Fahlman, Org. Electron. 2010, 11, 212.

7. G. Brocks, D. Cakir, M. Bokdam, M. P. de Jong, and M. Fahlman, Org. Electron. 2012, 13, 1793.

8. H. Fukagawa, S. Kera, T. Kataoka, S. Hosoumi, Y. Watanabe, K. Kudo, and N. Ueno, Adv. Mater. 2007, 19, 665.

9. M. T. Greiner, M. G. Helander, W. M. Tang, Z. B. Wang, J. Qiu, and Z. H. Lu, Nat. Mater. 2011, 11, 76.

10. M. Bokdam, D. Cakir, and G. Brocks, Appl. Phys. Lett. 2011, 98, 113303.

11. M. Fahlman, P. Sehati, W. Osikowicz, S. Braun, M. P. de Jong, and G. Brocks, J. Electron Spectrosc. Relat. Phenom. 2013, 190, 33.

12. D. Cakir, M. Bokdam, M. P. de Jong, M. Fahlman, and G. Brocks, Appl. Phys. Lett. 2012, 100, 203302.

13. W. Osikowicz, M. P. d. Jong, and W. R. Salaneck, Adv. Mater. 2007, 19, 4213.

14. I. E. Brumboiu, A. S. Anselmo, B. Brena, A. Dzwilewski, K. Svensson, and E. Moons, Chem. Phys.Lett. 2013, 568, 130.

15. R. Österbacka, C. P. An, X. M. Jiang, and Z. V. Vardeny, Science 2000, 287, 839.

16. T. Kirchartz, B. E. Pieters, J. Kirkpatrick, U. Rau, and J. Nelson, Phys. Rev. B 2011, 83, 115209.

17. L. J. A. Koster, E. C. P. Smits, V. D. Mihailetchi, and P. W. M. Blom, Phys. Rev. B 2005, 72, 085205 .

18. W. Tress, K. Leo, and M. Riede, Appl. Phys. Lett. 2013, 102, 163901.

19. W. J. Potscavage, A. Sharma, and B. Kippelen, Acc. Chem. Res. 2009, 42, 1758.

20. H. Aarnio, P. Sehati, S. Braun, M. Nyman, M. P. de Jong, M. Fahlman, and R. Osterbacka, Adv. Energy. Mater. 2011, 1, 792.

21. M. Bolognesi, D. Gedefaw, D. Dang, P. Henriksson, W. Zhuang, M. Tessarolo, E. Wang, M. Muccini, M. Seri, and M. R. Andersson, RSC Adv. 2013, 3, 24543.

22. D. Mühlbacher, M. Scharber, M. Morana, Z. Zhu, D. Waller, R. Gaudiana, and C. Brabec, Adv. Mater. 2006, 18, 2884.

23. E. G. Wang, L. T. Hou, Z. Q. Wang, S. Hellstrom, F. L. Zhang, O. Inganas, and M. R. Andersson, Adv. Mater. 2010, 22, 5240.

24. M. Tessarolo, D. Gedefaw, M. Bolognesi, P. Henriksson, W. Zhuang, M. Muccini, E. Wang, M. Seri, and M. R. Andersson, submitted 2014. 
25. A. Crispin, X. Crispin, M. Fahlman, M. Berggren, and W. R. Salaneck, Appl. Phys. Lett. 2006, 89, 213503.

26. X. Wang, E. Perzon, J. L. Delgado, P. d. 1. Cruz, F. Zhang, F. Langa, M. Andersson, and O. Inganäs, Appl. Phys. Lett. 2004, 85, 5081.

27. H. Y. Chen, J. H. Hou, S. Q. Zhang, Y. Y. Liang, G. W. Yang, Y. Yang, L. P. Yu, Y. Wu, and G. Li, Nat. Phot. 2009, 3, 649.

28. W. Zhuang, M. Bolognesi, M. Seri, P. Henriksson, D. Gedefaw, R. Kroon, M. Jarvid, A. Lundin, E. Wang, M. Muccini, and M. R. Andersson, Macromolecules 2013, 46, 8488.

29. K. Vandewal, K. Tvingstedt, A. Gadisa, O. Inganas, and J. V. Manca, Nat. Mater. 2009, 8, 904. 